\title{
WestVirginiaUniversity
}

THE RESEARCH REPOSITORY @ WVU

Graduate Theses, Dissertations, and Problem Reports

2013

\section{Three Essays on Economic Growth and Natural Resources}

Anne W. Walker

West Virginia University

Follow this and additional works at: https://researchrepository.wvu.edu/etd

\section{Recommended Citation}

Walker, Anne W., "Three Essays on Economic Growth and Natural Resources" (2013). Graduate Theses, Dissertations, and Problem Reports. 637.

https://researchrepository.wvu.edu/etd/637

This Dissertation is protected by copyright and/or related rights. It has been brought to you by the The Research Repository @ WVU with permission from the rights-holder(s). You are free to use this Dissertation in any way that is permitted by the copyright and related rights legislation that applies to your use. For other uses you must obtain permission from the rights-holder(s) directly, unless additional rights are indicated by a Creative Commons license in the record and/ or on the work itself. This Dissertation has been accepted for inclusion in WVU Graduate Theses, Dissertations, and Problem Reports collection by an authorized administrator of The Research Repository @ WVU.

For more information, please contact researchrepository@mail.wvu.edu. 


\title{
Three Essays on Economic Growth and Natural Resources
}

\author{
Anne W. Walker \\ Dissertation submitted to the \\ College of Business and Economics at \\ West Virginia University \\ in partial fulfillment of the requirements for the degree of \\ Doctor of Philosophy \\ in \\ Economics
}
Stratford M. Douglas, Ph.D., Chair
Andrew Young, Ph.D.
Tami Gurley-Calvez, Ph.D.
Timothy Phipps, Ph.D.
Santiago Pinto, Ph.D.
Department of Economics

Morgantown, West Virginia

2013

Keywords: sample selection, regions, resource curse, natural resources, Appalachian region, coal JEL Codes: C82, R12, R58, Q32, Q33, O18, R12. 


\title{
ABSTRACT \\ Three Essays on Economic Growth and Natural Resources
}

\begin{abstract}
Anne W. Walker
This dissertation is a collection of papers examining the relationship between resource intensity and economic growth in the Appalachian region of the United States. The first chapter develops a homogenous sample of counties within the Appalachian region and uses that sample to investigate how coal resources impact long-run per capita income growth. The Appalachian Regional Commission's definition of the Appalachian region is the one used most often by researchers, politicians, and the popular press. The uncritical use of this definition of Appalachia raises issues of both selection bias and excess heterogeneity in regression analysis of Appalachian income and growth. The ARC was created as part of President Johnson's war on poverty, and the geographical extent of its purview has been driven by politics and by the geography of poverty, neither of which is exogenous. It is well known that the use of endogenous variables to choose a sample creates bias and inconsistency in estimation of regression coefficients. To identify the counties that belong to the Appalachian region exogenously we use an algorithm based on three criteria: topography, contiguity, and prevalence of slavery in the 1860 census. We apply our sample to growth regressions using data from 1970 to 2008 , addressing the question of the existence of a resource curse from coal extraction. For this model we find strong evidence of excess heterogeneity, but not bias.
\end{abstract}

In the second chapter, I extend the analysis by exploring different possible measures for coal resource abundance. I use both a geologic based measure of "abundance" and a flow based measure of "dependence", and find evidence that coal abundance significantly reduces growth of per capita income over the long run with both measures. In addition, I use a wide variety of alternative measures of resource abundance suggested by the literature, all which indicate a negative systematic effect of resources on income growth. I account for the endogeneity of the each flow measure with instruments, and when I also account for the endogeneity of initial income, results indicate that a one standard deviation increase in the measure of resource intensity results in a 0.43 percentage point drop in average annual growth.

In the third chapter, I investigate several of the causes for the under-performance by many resource rich counties in the Appalachian region. I examine the effect of coal abundance on educational attainment, local (county) level education expenditure decisions, and local level taxation decisions. I find evidence that the educational attainment channel accounts for a significant portion of the negative effect of resource abundance. Coal resource abundance tends to reduce educational attainment, reducing human capital in a county, which in turn reduces per capita income growth over the long run. When attainment is measured by the share of the population that dropped out of high school, a one standard deviation increase in the measure of resource abundance reduces average annual growth by an estimated 0.125 percentage points. When educational attainment is measured instead by the share of the population that completed a college degree, average annual growth is reduced by an estimated 0.037 percentage points. I find no evidence that resource abundance affects the education expenditure allocation decisions of local county governments, nor do I find evidence that resource rich counties test to under tax their populations. 


\section{ACKNOWLEDGEMENTS}

I would like to thank my dissertation chair, Stratford Douglas, for his support throughout my graduate career. He went above and beyond his duties as an advisor and I am extremely fortunate to have had the opportunity to work with him. I would not have been able to accomplish what I have without his assistance, guidance, and friendship. I would also like to thank the remaining members of my committee, Andrew Young, Tami Gurley-Calvez, Santiago Pinto, and Tim Phipps not only for their comments and help during the writing process, but also for their guidance and mentorship. 


\section{Table of Contents}

Abstract......................................................... ii

Table of Contents................................................... iii

List of Tables and Figures....................................... iv

\section{Chapter 1: Sample Selection in Appalachian Research}

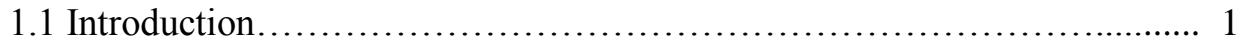

1.2 Sample Selection Method.......................................... 2

1.3 Application: The Coal Resource Curse.............................. 8

1.3.1 Model and Data.............................................. 8

1.3.2 Results..................................................... 13

1.4 Conclusions, Policy Implications, and Future Directions............... 15

\section{Chapter 2: An Empirical Analysis of the Resource Curse in the Appalachian Region}

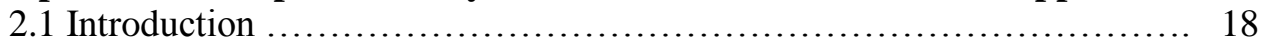

2.2 Brief Literature Review........................................ 21

2.2.1 Channels of the Resource Curse.............................. 21

2.2.2 Studies Using Sub-national Data............................... 22

2.2.3: Economic Growth and Natural Resources in Appalachia ......... 23

2.3 Measuring Resource Abundance versus Resource Dependence............. 25

2.4 Data and Model..................................................... 28

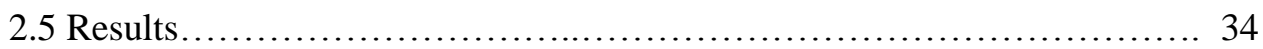

2.6 Conclusions and Policy Implications................................. 39

Chapter 3: An Empirical Analysis of the Resource Curse Channels in the Appalachian

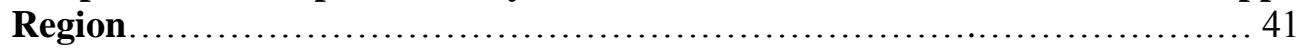

3.1 Introduction...................................................... 41

3.2 Educational Attainment Channel.................................... 41

3.2.1 Model...................................................... 44

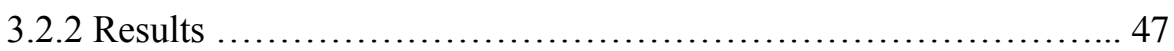

3.3 Educational Spending Channel.......................................... 52

3.3.1 Model....................................................... 53

3.3.2 Results ................................................ 54

3.4 Low Taxation Channel......................................... 56

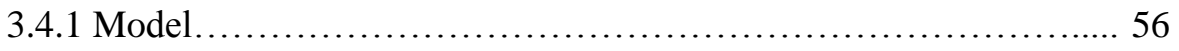

3.4.2 Results ................................................... 57

3.5 Conclusion ................................................... 59

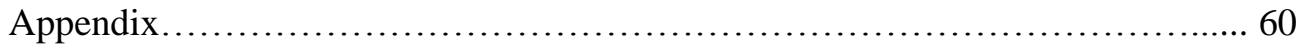

References.............................................................. 64 


\section{List of Tables and Figures}

\section{Tables:}

Table 1.1: Descriptive Statistics by Region within the 13 ARC States ................ 6

Table 1.2: Cross-Tabulation of Appalachian Counties and ARC Counties within ARC States

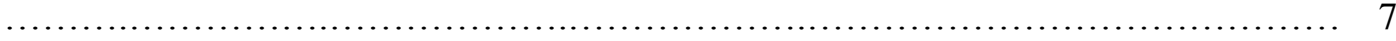

Table 1.3: Descriptive Statistics by Non-Overlapping Regions ..................... 8

Table 1.4: Descriptions of Variables and Descriptive Statistics for 1069 counties in Thirteen ARC

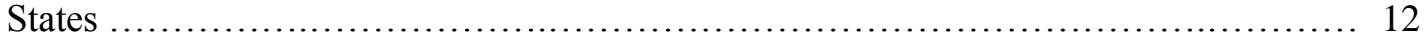

Table 1.5: Growth Regression Results ....................................... 14

Table 2.1: Descriptive Statistics for Coal0 Variable ............................... 27

Table 2.2: Descriptive Statistics for NR (Coal Revenue as a Share of Personal Income)

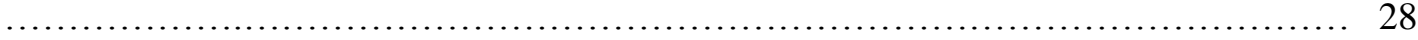

Table 2.3: Variable Descriptions and Sources ..................................... 33

Table 2.4: Descriptive Statistics ............................................ 33

Table 2.5: Estimates of the effect of Resource Abundance on Economic Growth (Equation 2a)

Table 2.6: Estimates of the effect of Resource Dependence on Economic Growth (Equation 2b)

Table 2.7: Alternative Measure of Resource Abundance ........................... 38

Table 2.8: Alternative Measure of Resource Abundance: Descriptive Statistics............ 39

Table 2.9: Estimates of the effect of Resource Dependence on Economic Growth using

Alternative measures of resource abundance ........................................ 39

Table 3.1: Estimates of the effect of Resource Abundance and Educational Attainment on

Economic Growth (Equation 3.1) .............................................. 49

Table 3.2: Estimates of the effect of Coal Resource Abundance on Educational Attainment

(Equation 3.2) ............................................................ 50

Table 3.3: Estimates of the Indirect Effect of Coal Abundance on Education .............. 51

Table 3.4: Mean Education Expenditure Share, by Year ............................. 53

Table 3.5: Estimates of the effect of Resource Abundance on County Educational Expenditure

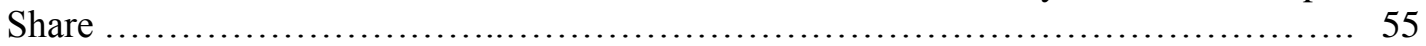

Table 3.6: Mean Property Taxes Per Capita, by Year (in Dollars) .................... 57

Table 3.7: Mean Total County Taxes Per Capita, by Year (in Dollars) .................. 57

Table 3.8: Estimates of the effect of Resource Abundance on Tax Revenues Per Capita of County

Government ................................................................. 59

Figures:

Figure 1.1: Map Showing the Distribution of the Slave Population of the Southern States

of the United States, by Edwin Hergesheimer............................ 5

Figure 1.2: Appalachian County Designations .............................. 7

Figure 2.1: Real per Capita Income, Coal versus Non-Coal Counties in Appalachia

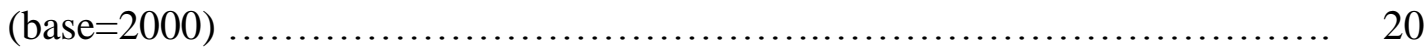

Figure 2.2: Real Price of Bituminous Coal and Mean Growth of Real Per Capita Personal

Income of Coal and Non-Coal Appalachian Counties ......................... 29

Figure 2.3: Figure 2.3: Mean Growth of Per Capita Personal Income of Coal and NonCoal Appalachian Counties ............................................ 29

Figure 3.1: Share of Population without a High School Diploma, by Year ....... 43

Figure 3.2: Share of Population with a Bachelor's Degree or Higher, by Year ..... 44 


\section{Chapter 1 \\ Sample Selection in Appalachian Research}

\subsection{Introduction}

Use of the Appalachian Regional Commission (ARC) definition of Appalachia has become widespread in academia and the popular press. The ARC was created in 1965 as part of President Johnson's war on poverty, and the counties under its purview were deliberately chosen for their low income levels and growth rates. At the same time, the homogeneity of the region attracts social science researchers seeking natural experiments to test hypotheses about the determinants of poverty and income growth rates using regression analysis. Unfortunately, regression coefficients estimated from a sample chosen on criteria that are correlated with a regression's dependent variable will be biased and inconsistent (Heckman, 1979), so the ARC's Appalachian counties constitute a problematic sample for such regressions. To avoid sample selection bias in Appalachian income, poverty, and income growth regressions while maximizing the homogeneity of the sample, we therefore offer an alternative algorithm for identifying the sample that is based on three criteria that are exogenous to income and income growth: topography, contiguity, and prevalence of slavery in the 1860 census.

We demonstrate our method of sample selection by using it to select samples for a set of county-level panel data regressions on per capita income growth that seek evidence of a "resource curse" from coal extraction. Most previous studies of the resource curse have employed international data, which do not allow for sharp identification of the effects of resource abundance. This difficulty of identification arises from the great diversity among countries, compounded by measurement problems, omitted variables, and multicollinearity. To address these problems in the resource-curse literature, van der Ploeg (2011, p. 381) suggests, "The road forward might be to exploit variation within a country where variables that might confound the relationship between resources and macroeconomic outcomes do not vary and the danger of spurious correlation is minimized." Thus, if regions are thought of as experimental subjects receiving a random treatment of resource endowments, the experiment will more reliably detect the treatment effect if the subjects are otherwise homogenous.

The counties of the Appalachian region of the United States possess relative uniformity of culture, topography, and history that developed over a period of isolation from the rest of the country. They, therefore, present a nearly ideal population for the type of study suggested by van der Ploeg. The approximately equal number of treatment (i.e., coal-bearing) and control counties within the region also provide a desirable balance of experimental design. The ARC's definition 
of the Appalachian region, however, introduces unwanted heterogeneity and raises the possibility of bias and inconsistency due to the endogeneity of its sample selection process. We propose to ameliorate both endogenous sample selection and excess heterogeneity by using exogenous variables to identify counties whose primary source of diversity is the presence or absence of commercially mineable coal. Our objective, quite simply, is to obtain an Appalachian county sample that is as homogeneous as can be obtained using exogenous criteria.

Comparing our regression results from different samples, we find evidence of excess heterogeneity but not bias due to sample selection. Despite the lack of bias in our particular application, the methods and reasoning that we use in selecting our sample have implications for future studies of development in resource-rich regions, including those whose exploitable resource base has recently expanded due to the development of new extraction technologies. Better sample selection techniques will allow more accurate conclusions about the effects of resource abundance on economic growth, which will provide a firmer basis for policy decisions affecting the speed and nature of resource development.

\subsection{Sample Selection Method}

The Appalachian region south of New England possesses a distinct and robust culture that flows from its unique history. The immigrants settling this region in the eighteenth century were primarily of Scotch-Irish extraction, as opposed to the English, German, and African origins of the inhabitants of the Southern lowlands. There is a large literature describing distinctive characteristics of the southern Appalachian highlanders, including their close ties to land and family, distrust of outsiders, pugnaciousness, and independent spirit. ${ }^{1}$ For more than a century after the American Revolution there was little immigration into the region, and a culture of defiant independence grew up among the subsistence farmers living in these isolated uplands. One marker of the region's distinctive culture and economy was the hostility of its inhabitants to the Confederacy in the Civil War, which led to the wartime secession of West Virginia from Virginia. Despite (or because of) its semi-pariah status among urban Americans, the "hillbilly" culture of the Southern Appalachians has persisted. More than that, it has contributed highly visible elements to mainstream American culture, including the coonskin-capped pioneer icon, the Clampett and Snopes families, roots of bluegrass and country music, and NASCAR auto racing. Immigrants from other cultures that came to work in the Appalachian coal fields and

\footnotetext{
${ }^{1}$ For example, Fischer (1989) provides an exhaustive treatment of the Appalachian Scotch-Irish culture, with emphasis upon its origins in the violent and impoverished regions on the border of Scotland and England.
} 
forests in the last century were largely absorbed into this culture, which still predominates in the region. Despite considerable economic development in the past half-century, poverty still predominates in the region as well.

The Appalachian Regional Commission was created in 1965 as part of President Johnson's war on poverty. Its identification of the counties under its purview was then, and has continued to be, much affected by the politics and geography of poverty. The Kennedy administration established the Presidential Appalachian Regional Commission (PARC) in 1963, which consisted of federal officials and the governors of nine Appalachian states. ${ }^{2}$ The PARC hired a staff of academics that produced a report identifying 340 Appalachian counties in ten states including Ohio (ARC, 1964). To aid passage of the Appalachian Regional Development Act of 1965, which created the ARC, Congress further expanded the list of Appalachian states to include South Carolina (Bradshaw, 1992). Mississippi and New York were added to the list in 1967, and more counties have been added since to bring the current total to 420 counties in 13 states. Adding counties to the ARC is a purely political process (Bradshaw, 1992), but its programs are designed to help poor counties, and poorer counties are therefore chosen for membership. For example, most Mississippi counties were added in 1967 explicitly because of their poverty. Though poor, most of these counties are not topographically, demographically, or culturally part of the Appalachian region. Similarly, many counties in topographically flat but economically depressed northeastern Ohio have been added to the ARC since that region's economic decline began in the 1970s. Thus, the ARC's county designations are clearly not exogenous to income growth rates, raising issues of bias and inconsistency in coefficient estimates from growth regressions. Addition of counties that do not share the Appalachian culture and history has added to the heterogeneity of the sample as well, which decreases the precision of estimates.

The Appalachian culture is tightly tied to the rugged topography of the Appalachian countryside. To identify the counties that belong to the Appalachian region we have therefore used an algorithm based on three exogenous criteria that reflect Appalachian landforms and the exogenous constraints they place on economic activity. One criterion is the set of Land Surface Form Topography Codes compiled by the U.S. Geological Survey (USGS, 1970). These codes, which are listed in Appendix 3, range from 1 (Flat Plains) to 21 (High Mountains), and broadly increase in relief as the numbers increase. The progression of codes is not perfectly monotonic,

\footnotetext{
${ }^{2}$ The original nine ARC states were Alabama, Georgia, Tennessee, North Carolina, Kentucky, West Virginia, Virginia, Maryland, and Pennsylvania.
} 
however, which led to some difficult implementation problems. For example, it is unclear whether "plains with low mountains" (code 11) are more or less mountainous than "open hills" (code 14), and it is not obvious whether code 8 counties ("tablelands, very high relief") should be counted as Appalachian. After some study, it became clear to us that we needed other exogenous criteria to classify some counties.

To supplement our sample selection algorithm we use the percentage of slaves in the county as enumerated in the 1860 Census. Prevalence of slavery within a county indicated its economic system, demography, culture, social relationships, and political loyalties. Because of poor soil and rough terrain, plantation agriculture and slavery never took hold in the Southern Appalachians. The inverse correlation between slavery prevalence and mountainous terrain is readily apparent in Edwin Hergesheimer's famous 1861 "Map Showing the Distribution of the Slave Population of the Southern States of the United States," an official publication of the U.S. Census Bureau that is reproduced in Figure 1.1. ${ }^{3}$ Our third criterion is geographical contiguity with other Appalachian counties, including information about the continuation and prevalence of ridges and mountainous terrain obtained from the terrain feature of Google Maps maps.google.com.

\footnotetext{
${ }^{3}$ See http://www.press.uchicago.edu/books/akerman/maps_slavery.html for a brief history of the significance of this map. We downloaded our copy from the Library of Congress, http://www.loc.gov/item/99447026, specifically the 15.9 MB jp2 file at http://lcweb2.loc.gov/gmd/gmd386/g3861/g3861e/cw0013200.jp2.
} 


\section{Figure 1.1: "Map Showing the Distribution of the Slave Population of the Southern States of the United States," by Edwin Hergesheimer}

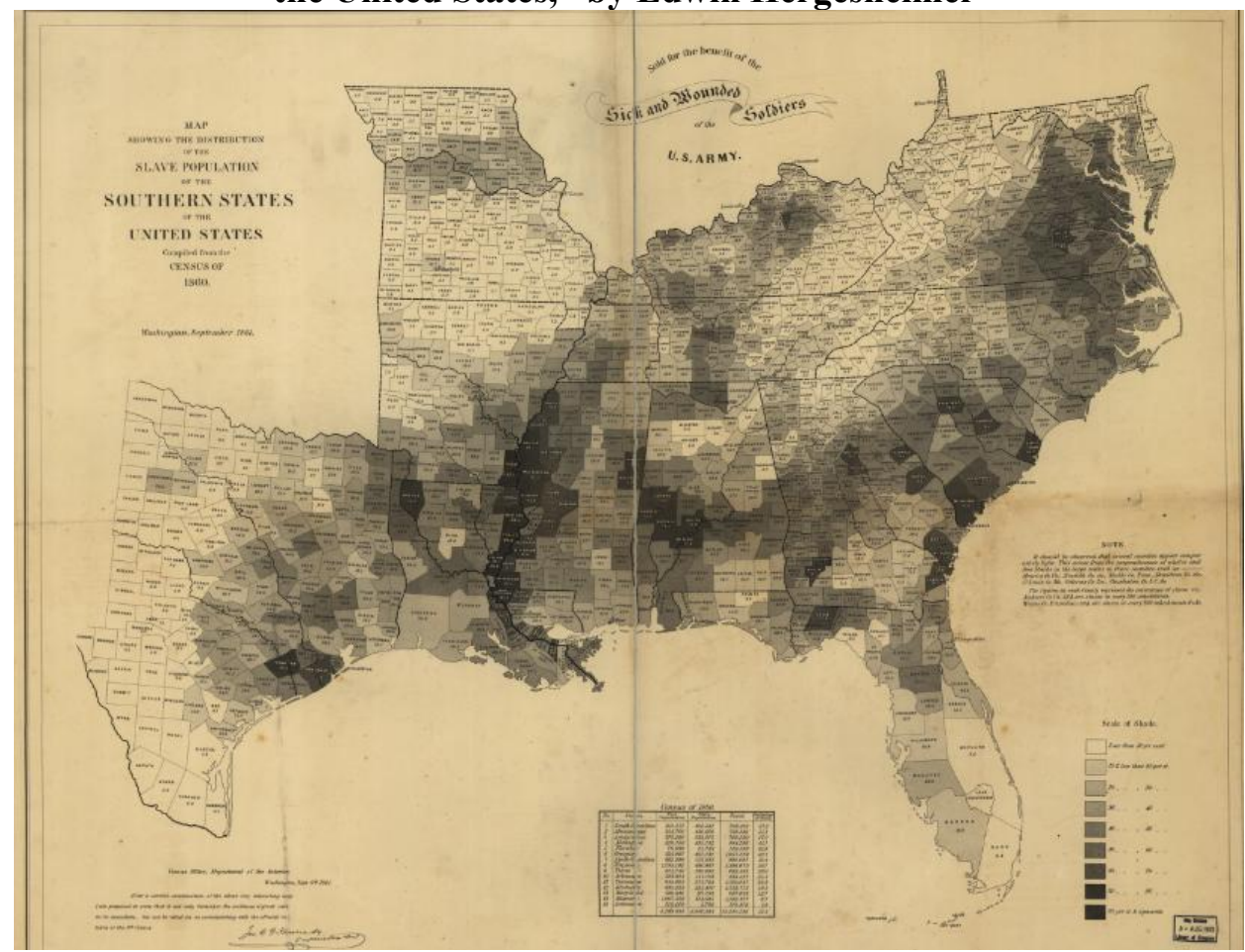

Source: U.S. Bureau of the Census, 1861.

Our algorithm identifies both a narrow set of 250 "core" Appalachian counties with both mountainous terrain and low slave percentages, and a more broadly defined set of 409 counties with either smoother terrain and fewer slaves or rougher terrain and more slaves. Specifically, the core Appalachian counties include all contiguous counties with USGS topography codes exceeding 14 and 1860 Census enslavement ratios of 10 percent or less. We also include in the Appalachian core counties possessing topography codes of five through nine and 1860 Census slave percentages of 10 percent or less. Counties containing Chattanooga and Knoxville Tennessee, Asheville North Carolina, and Charleston West Virginia were included in the Appalachian core despite their relatively high slave percentages (10 to 17 percent) because of their high topographic relief and their roles as centers of Appalachian culture and commerce. ${ }^{4}$ To designate our more broadly-defined Appalachian counties, we added 159 counties to the 250 in the core. Most of these additional counties have topography codes of five to nine or higher, all have slave percentages above 10 percent, and all are contiguous to other Appalachian counties. The additional counties in the broadly-defined Appalachian region include contiguous counties with topography codes of ten and 1860 slave populations of $20-28$ percent, as well as a few

\footnotetext{
${ }^{4}$ We excluded Birmingham, Alabama, from the core (but not the broad) Appalachian designation because of Jefferson County, Alabama's 22 percent slave ratio in 1860.
} 
counties in South Carolina and Virginia with higher slave percentages but topography codes of 20 ("low mountains").

Table 1.1 shows that Appalachian per capita personal income is relatively low, and it drops a little as one goes deeper into Appalachia. The ARC and Narrow definitions of Appalachia are similar in terms of income, poverty rates, and unemployment rates. In addition, the ethnicity and demographic data presented in Table 1.1 provide some support for the idea that the Appalachian counties are similar to each other and different from non-Appalachian counties. For example, Appalachian populations are about 25 percentage points more ethnically white than the other counties in the ARC states, and their ethnicity is less variable from county to county. Appalachian residents are slightly more likely to claim British or Irish descent than residents of other regions in the ARC states, and are less likely to claim German descent. They are also slightly more likely to be native English speakers, which is not surprising given the relative paucity of Hispanic and other recent immigrants in Appalachian counties. The ARC's willingness to add fringe counties to its purview on the basis of poverty means that ARC-designated Appalachian counties are less white and more variable in ethnicity than those designated by our algorithm, though they are about equally poor.

\section{Table 1.1: Descriptive Statistics by Region within the 13 ARC States}

\begin{tabular}{|c|c|c|c|c|c|c|c|c|}
\hline \multirow[b]{3}{*}{ Real Per Capita Income } & \multicolumn{8}{|c|}{ Appalachian Status Definition } \\
\hline & \multicolumn{2}{|c|}{ Not App } & \multicolumn{2}{|c|}{ Broadly App } & \multicolumn{2}{|c|}{ Core App } & \multicolumn{2}{|c|}{$\mathrm{ARC}$} \\
\hline & Mean & Std. & Mean & Std. & Mean & Std. & Mean & Std. \\
\hline Personal Income 1970 & 11975 & 3478 & 10936 & 2779 & 10456 & 2828 & 10622 & 2573 \\
\hline Personal Income 1980 & 13644 & 4057 & 12653 & 2792 & 12207 & 2803 & 12383 & 2700 \\
\hline Personal Income 1990 & 16920 & 5412 & 14841 & 3622 & 13999 & 3385 & 14502 & 3373 \\
\hline Personal Income 2000 & 19748 & 6706 & 17060 & 4300 & 16005 & 3855 & 16673 & 4050 \\
\hline White 1960 & 0.708 & 0.187 & 0.964 & 0.052 & 0.979 & 0.032 & 0.929 & 0.119 \\
\hline White Non-Hispanic 1990 & 0.736 & 0.159 & 0.965 & 0.047 & 0.979 & 0.026 & 0.937 & 0.108 \\
\hline Poverty Rate 1990 & 0.174 & 0.087 & 0.177 & 0.079 & 0.194 & 0.086 & 0.186 & 0.078 \\
\hline Number of Counties & \multicolumn{2}{|c|}{660} & \multicolumn{2}{|c|}{409} & \multicolumn{2}{|c|}{250} & \multicolumn{2}{|c|}{420} \\
\hline Number of Coal Counties & \multicolumn{2}{|c|}{13} & \multicolumn{2}{|c|}{174} & \multicolumn{2}{|c|}{142} & \multicolumn{2}{|c|}{181} \\
\hline
\end{tabular}

Figure 1.2 illustrates the differences and commonalities among the ARC, core, and broad definitions of Appalachia, and Table 1.2 provides cross-tabulations. Table 1.3 provides some descriptive statistics of the counties that are affected by differences among the various methods of designating the region. Our broad definition of the Appalachian includes 353 (84 percent) of the ARC counties, though we exclude 113 of those common counties from our "core" Appalachian 
designation. These 113 include some with moderately high slave percentages, concentrated in Alabama, Mississippi, East Tennessee, and central Kentucky, in the New, Holston, and Shenandoah river valleys of Virginia, and in the Carolina Piedmont. They also include some ARC counties with moderate topographical relief in Ohio and New York.

Table 1.2: Cross-Tabulation of Appalachian Counties and ARC Counties within ARC States

\begin{tabular}{|c|c|c|c|c|c|c|c|c|c|}
\hline \multirow{5}{*}{ ARC } & & \multicolumn{5}{|c|}{ Appalachian Broadly Defined } & \multicolumn{3}{|c|}{ Appalachian Core } \\
\hline & & No & Yes & Total & & & No & Yes & Total \\
\hline & No & 593 & 56 & 649 & ARC & $\mathrm{No}$ & 639 & 10 & 649 \\
\hline & Yes & 67 & 353 & 420 & & Yes & 180 & 240 & 420 \\
\hline & Total & 660 & 409 & 1069 & & Total & 819 & 250 & 1069 \\
\hline
\end{tabular}

Figure 1.2: Appalachian County Designations

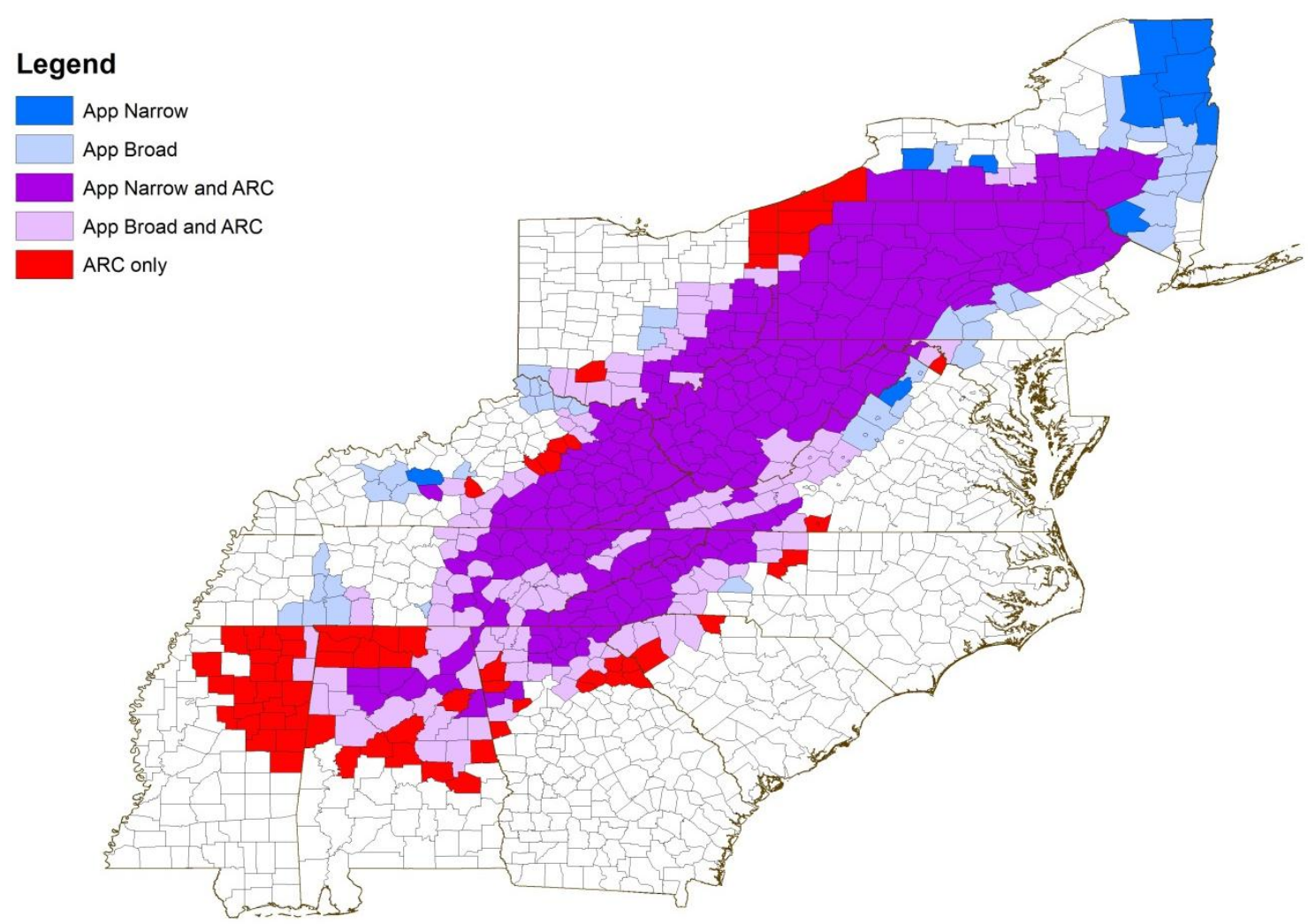

There are significant discrepancies between even our broad definition of Appalachia and the ARC definition of Appalachia. Most of the 67 ARC counties that our method excludes entirely from Appalachia (ARC/Not-Broad in Table 1.3) are poor counties located on the fringe 
of Appalachia in Alabama, Mississippi, and northeastern Ohio. Table 1.3 shows that these ARC counties are overall much less ethnically white than the others, and the standard errors of the ethnicity variables indicate much more ethnic variability as well. Their poverty levels and incomes are similar to those of the Appalachian region listed in Table 1.3, but their poverty may be more driven by the legacy of slavery or the decline of manufacturing than is the case in Appalachia proper.

We also include 56 non-ARC counties in our broad definition of Appalachia, of which ten are defined as part of the Appalachian core. The 46 broadly Appalachian, but non-core and non-ARC, counties are concentrated in the middle Tennessee River valley, the coal regions of west central Kentucky, the rugged country around the Ohio River west of Cincinnati, and the eastern ridges of the Alleghenies in Virginia, Maryland, Pennsylvania, and New York. The ten counties included in core Appalachia but excluded from the ARC are concentrated in the Adirondacks and Catskills of New York, but also include Shenandoah County, Virginia and Grayson County, Kentucky, which enslaved only 5.5 percent and 4.4 percent of their inhabitants, respectively, in 1860. Figures in Table 1.3 indicate that these 56 counties are similar in ethnicity to the rest of Appalachia, but their relatively low poverty rates and high incomes probably explain their exclusion from the ARC.

Table 1.3: Descriptive Statistics by Non-Overlapping Regions

\begin{tabular}{|c|c|c|c|c|c|c|c|c|}
\hline \multirow{5}{*}{$\begin{array}{l}\text { Real Per Capita Income } \\
\text { Personal Income } 1970\end{array}$} & \multicolumn{8}{|c|}{ Appalachian Status Definition } \\
\hline & \multicolumn{2}{|c|}{$\begin{array}{c}\text { ARC } \\
\text { /NotBroad }\end{array}$} & \multicolumn{2}{|c|}{ Broad/NotCore } & \multicolumn{2}{|c|}{ Core/NotARC } & \multicolumn{2}{|c|}{ Broad/NotARC } \\
\hline & Mean & Std. & Mean & Std. & Mean & Std. & Mean & Std. \\
\hline & \multicolumn{2}{|c|}{$\mathrm{n}=67$} & \multicolumn{2}{|c|}{$\mathrm{n}=159$} & \multicolumn{2}{|c|}{$\mathrm{n}=10$} & \multicolumn{2}{|c|}{$\mathrm{n}=56$} \\
\hline & 10934 & 2510 & 11759 & 2591 & 12768 & 1892 & 13291 & 2825 \\
\hline Personal Income 1980 & 12507 & 2746 & 13422 & 2688 & 13088 & 1642 & 14507 & 2700 \\
\hline Personal Income 1990 & 15170 & 3581 & 16281 & 3781 & 16611 & 2515 & 17776 & 4064 \\
\hline Personal Income 2000 & 17363 & 4115 & 18906 & 4856 & 17858 & 2506 & 20324 & 4549 \\
\hline White 1960 & 0.75 & 0.188 & 0.939 & 0.069 & 0.981 & 0.016 & 0.968 & 0.03 \\
\hline White Non-Hisp. 1990 & 0.779 & 0.177 & 0.939 & 0.074 & 0.953 & 0.04 & 0.954 & 0.043 \\
\hline Poverty Rate 1990 & 0.189 & 0.72 & 0.152 & 0.057 & 0.12 & 0.043 & 0.123 & 0.053 \\
\hline
\end{tabular}

\subsection{Application: The Coal Resource Curse}

\subsubsection{Model and Data}

In this section we describe a simple panel data regression model designed to search for a coal resource curse effect in Appalachia. As discussed above, we rely upon the relative 
homogeneity of our sample to minimize the influence of omitted variables, allowing us to specify a parsimonious model with only a few control variables. Our resource abundance measure CoalO varies little through time, as it simply indicates whether or not a county contains commercially relevant coal deposits. Since the variation in CoalO is almost entirely in the cross-sectional dimension, we employ cross-sectional fixed effects only at the state level.

The search for a resource curse has generated a lively debate in the literature. Although the debate has attracted interest from economists since Adam Smith, a recent upsurge of interest has followed from a series of papers by Sachs and Warner $(1995,1997,2001)$. Van der Ploeg (2011) provides the most recent survey of this literature, but useful surveys are also available from Ross (1999), Auty (2001), and Barbier (2005) as well. Most empirical work in this area has used cross-sectional analysis on international data, comparing long-run economic growth rates across large samples of both developed and developing countries. The empirical equations echo those found in the empirical growth model literature, which are derived from the neoclassical Solow growth model.

Very few previous studies have used sub-national data to address the resource curse question. Michaels (2011) uses county-level data to investigate the effect of oil resources on a variety of measures, including personal income and employment density, and devotes much attention to the problem of sample selection. In contrast to much of the rest of the empirical resource curse literature, he finds a positive effect of resource abundance on employment density and income growth, which he attributes to agglomeration economies. His paper is also of special interest here because he attempts to limit heterogeneity by drawing his sample only from counties within 200 miles of an oil resource.

James and Aadland (2011) found significant negative growth effects of resource abundance using a national cross section of 3092 counties over the 1980-1995 time period. Papyrakis and Gerlagh (2007) also found a resource curse using state-level U.S. data (specifically, they estimated that a one percent increase in resource abundance decreases growth by about 0.047 percent). There are also a few unpublished papers using sub-national data. They include Caselli and Michaels (2009), which looks at the effect of oil resources in different regions of Brazil, and dissertation chapters by Sen (2010), Corey (2008), and Dunn (2008), which employ U.S. data measured at the state and (in the case of Sen) county level. Like James and Aadland (2011), these latter three studies analyze the United States as a whole and define resource abundance broadly, whereas we focus on Appalachia and coal in order to identify the mechanism sharply. 
A few recent papers examine the resource curse specifically in the Appalachian region, and most of the empirical results are broadly in line with our finding of a modest negative effect of coal mining on income growth. Deaton and Niman (2012), and Partridge, Betz, and Lobao (2012) both examine the problem using poverty rates as the dependent variable. Deaton and Niman (2012) examined poverty as a function of mining employment in Appalachia and estimated that a one percent increase in mining employment results in a net increase in poverty of approximately 15 percent. Partridge, Betz, and Lobao also find a mostly positive association between coal mining and poverty, but they also find evidence that the association has weakened recently. Black, McKinnish, \& Sanders (2005b) examined the effects of coal mining on earnings during the boom and bust cycle of the late 1970s to early 1980s, and found that the down-cycle effects predominated, as earnings grew 5 percent faster during the boom, but 5.5 percent slower during the bust. Harkness (2010) used a sample of Kentucky counties to examine the resource curse and found no conclusive evidence of a resource curse associated with coal.

Economic growth models such as the one we use in this study have been employed in the study of other issues in Appalachia. These include a recent paper by Ziliak (2011), one of many that seeks to measure the efficacy of the ARC in reducing poverty by comparing outcomes in ARC counties to similar counties that are not included in the ARC. Ziliak (2011) compares Appalachian counties to adjacent and surrounding counties, and to other U.S. rural counties. Isserman and Rephann (1995) used a quadratic distance metric to match Appalachian counties to their twins outside of Appalachia. Glaeser and Gottlieb (2008) compare Appalachian counties to other non-coastal counties within their respective states.

Our specific question involves a comparison of counties within Appalachia. We specify a panel data regression model of annualized growth rates, measured as the difference in log per capita personal income divided by the length of the period, $g_{\text {it }}$ for county $i$ in state $s$ at time $t$ :

$$
g_{i t}=\beta_{1} \operatorname{LnY} Y_{i t}+\beta_{2} \operatorname{Coal0}_{i t}+\beta_{3} X_{i t}+\beta_{4} Y r_{t}+\mu_{s}+u_{i t}
$$

where $\operatorname{Ln} Y_{i t}$ is the level of per capita personal income in county $i$ at the beginning of time period $t$, Coal $_{i t}$ is a measure of coal resource abundance, $\mu_{s}$ is a state fixed effect, and $X_{i t}$ is a vector of exogenous variables. The standard Solow model calls for a region to exhibit conditional convergence to a balanced growth path, which implies a negative coefficient, $\beta_{1}$, on the initial income variable. We include state fixed effects because institutional characteristics such as income, severance, sales, and inheritance taxes, broad infrastructure and educational policy, judicial system, much law enforcement (including environmental law enforcement), and corruption are all strongly affected by statewide institutions. We do not include county fixed 
effects because the variation in coal resource abundance is cross-sectional in nature and varies little through time, and county fixed effects would remove all time-invariant, cross-sectional differences.

An ideal resource abundance variable should be exogenous, and it should indicate the presence of the resource in a way that reflects both the resource extraction process and the hypothesized transmission channels for the resource curse. In the current study, we believe that if there is an Appalachian coal resource curse the primary transmission channels for it would be through 1) depressed educational attainment by students who terminate their formal education early to take relatively highly paid coal mining jobs that do not require much formal education, 2) economic disruption and long-term unemployment caused by the boom and bust cycle, and perhaps 3) long-term health effects. The effects of these channels, if they exist at all, would persist over a long time period; therefore our resource abundance variable should not be too sensitive to current production, or it should employ a lag structure of some length. Simplicity of both construction and interpretation are also desirable. We therefore employ an indicator variable Coalo, equal to one if the county has ever produced and sold any coal, as of the initial year of the time period. This dummy variable is likely exogenous because the Appalachian coal fields are mature: nearly all of the counties, including all of the major coal producing counties, initiated coal production before our sample period. ${ }^{5}$ The samples are well balanced with respect to this variable: as of 1990, 46 percent of the ARC counties, 61 percent of our core, and 47 percent of our broadly defined Appalachian counties had produced at least some coal.

Our choice of control variables $x_{i t}$ is limited by our research goal of estimating a reduced form equation. Past researchers, seeking to explore possible mechanisms or channels for the resource curse, have included a variety of control variables thought to influence the long-run average growth of an economy, many of which introduced endogeneity concerns. To mitigate endogeneity problems, we limit the number of controls. The drawback of this research strategy is that it does not allow us to determine the channel of operation of the resource curse, if any. On the other hand, the strategy does allow us a cleaner test for the existence of the resource curse, given a homogenous sample.

Appalachian poverty is often attributed to geographic isolation and consequent lack of access to transportation, financial centers, higher education, and other growth-enhancing amenities associated with urban areas. Accordingly, we have included dummy variables derived

\footnotetext{
${ }^{5}$ In this respect, our CoalO variable resembles the resource abundance variable used by Michaels (2011), which was a measure of the total amount of oil resource that existed prior to exploitation.
} 
from the USDA's Rural-Urban Continuum ("Beale") Codes. Beale Codes are available for 1974, 1983, 1993, and 2003, and are based primarily on data from the previous census. So we treat them as exogenous beginning-of-period values for their respective decades. Because they are non-monotonic, we use them to create two dummy variables that indicate rural and metro counties, respectively.

Table 1.4: Descriptions of Variables and Descriptive Statistics for 1069 counties in Thirteen ARC States

\begin{tabular}{|c|c|c|c|c|c|}
\hline Variable & Description & Mean & Std. Dev. & Min & Max \\
\hline $\begin{array}{l}\text { Dependent } \\
\text { Variable }\end{array}$ & $\begin{array}{l}\text { Average annual growth rate of per capita } \\
\text { personal income, net of taxes and } \\
\text { transfers }\end{array}$ & 0.013 & 0.013 & -0.042 & 0.093 \\
\hline $\begin{array}{l}\text { Initial } \\
\text { Income }\end{array}$ & $\begin{array}{l}\text { Log of beginning of period log per capita } \\
\text { personal income }\end{array}$ & 9.554 & 0.331 & 8.322 & 11.249 \\
\hline $\begin{array}{l}\text { Metro } \\
\text { County }\end{array}$ & $=1$ if Beale code $\leq 3$ (Metro area) & 0.325 & 0.468 & 0 & 1 \\
\hline Rural County & $\begin{array}{l}=1 \text { if Beale code } \geq 7 \text { (Very Rural, or } \\
\text { urban population }<20,000 \text {, not adjacent } \\
\text { to an urban county) }\end{array}$ & 0.377 & 0.485 & 0 & 1 \\
\hline $\begin{array}{l}(\mathrm{dOil} \text { Price }) \mathrm{x} \\
(\text { Coal0 })\end{array}$ & $\begin{array}{l}\text { (Percent change in real oil price over } \\
\text { period) times Coal0 }\end{array}$ & 0.079 & 0.473 & -0.940 & 1.650 \\
\hline Coal 0 & $\begin{array}{l}=1 \text { if county has produced coal } \\
\text { commercially, as of initial year of period } \\
(220 \text { of } 1069 \text { as of year } 2000)\end{array}$ & 0.203 & 0.402 & 0 & 1 \\
\hline
\end{tabular}

The panel data structure includes four time periods - the decades beginning in 1970, 1980, and 1990, along with the nine-year period 2000-2008, which are used to construct the time fixed effects dummies. The inclusion of time fixed effects is standard in panel growth models, as they essentially transform each variable into a difference from its cross-sectional mean as of time $t$, which controls for the business cycle and other shocks common to all counties at a given time. To control for the cyclical and secular effects of changes in energy prices on counties that produce coal, we include an interaction variable that is the product of the (log-difference) percentage change in real oil price and CoalO. ${ }^{6}$

We obtained the data for our economic growth and initial income variables from the Bureau of Economic Analysis's Regional Economic Accounts. We adjusted the measure by subtracting government transfers, and deflated to constant-year terms using a base year of 2000 . Coal production data were obtained from the U.S. Geological Survey (USGS) and the U.S.

\footnotetext{
${ }^{6}$ The average real price of oil in $1970,1980,1990$, and 2000 was $\$ 19.65, \$ 102.26, \$ 39.80$, and $\$ 35.76$, respectively.
} 
Energy Information Administration (EIA), and the Beale codes were obtained from the U.S. Department of Agriculture (USDA). Coal and oil price data were obtained from the EIA.

\subsubsection{Results}

We estimated equation (1) using time and state-level fixed effects in panel data regressions, and report the results in Table 1.5 along with robust standard errors. There are four columns of results from four different samples. The column labeled "All" includes all counties in the 13 Appalachian states, regardless of whether or not the counties are part of Appalachia. The other columns correspond to the samples chosen as explained in detail above.

The coefficients shown in Table 1.5 are of expected signs and reasonable magnitudes. The estimated coefficient on beginning of period income $\left(\beta_{1}\right)$ is negative and significant at the one percent level in all specifications, indicating conditional convergence of per capita income. The asymptotic rate of convergence can be inferred (Higgins, Levy, \& Young, 2006) from the BOP income coefficient estimate as $c=1-(T \beta) 1 / T$. Coefficient estimates range from -0.013 to 0.023 , implying a convergence rate of 1.3 percent to 2.3 percent per year. Appalachian counties are estimated to have faster rates of convergence. As expected, the coefficient estimates for the metro dummy variable is positive and significant. Estimates for the rural dummy variable coefficient are of the expected sign, but not significant. Coefficient estimates for the interaction variable between the change in real oil price and the CoalO dummy variable are all positive and significant at the 1 percent level, consistent with energy prices' well-known short-term positive effect on income in coal-producing Appalachian counties.

The coefficient estimates on CoalO suggest a moderate but significant coal resource curse, slowing expected economic growth by an estimated 0.3 percent to 0.4 percentage points per year. Over time, even such small decreases in average annual income growth have a sizeable impact on income levels. For example, a drop in average annual income growth of 0.4 percentage points results in income levels being lowered by about 17.3 percent over forty years, with compounding. Therefore, our estimates indicate that counties with coal mining present were 15 to 20 percent poorer by the end of the forty year period covered by our sample than similarly rural counties within the same state that started with the same income but lacked a coal resource. Following Black et al. (2005b), we also estimated the model with (state)*(time) interaction terms to account for state-specific growth rate variations through time. We report the results in Appendix 4. Generally, this alternative model finds a smaller but still significant negative association between coal mining and economic growth. The estimated effect of the coal resource shrinks enough to become statistically insignificant for the Core Appalachian counties. 
Table 1.5: Growth Regression Results

Dependent Variable: Annualized Growth Rates of Per Capita Personal Income 1970-2008 Sample Size: T=4 (1970-2008), N=409 Counties, total obs. $=1636$

\begin{tabular}{|c|c|c|c|c|}
\hline & \multirow{2}{*}{$\begin{array}{c}\text { ALL } \\
\text { COUNTIES }\end{array}$} & \multicolumn{3}{|c|}{ APPALACHIAN } \\
\hline & & BROAD & CORE & ARC \\
\hline Intercept & $\begin{array}{c}0.1309 * * * \\
(0.0246)\end{array}$ & $\begin{array}{c}0.1958 * * * \\
(0.0144)\end{array}$ & $\begin{array}{c}0.2214 * * * \\
(0.0300)\end{array}$ & $\begin{array}{c}0.2033 * * * \\
(0.0228)\end{array}$ \\
\hline Initial Income & $\begin{array}{c}-0.0133 * * * \\
(0.0026)\end{array}$ & $\begin{array}{c}-0.0202 * * * \\
(0.0015)\end{array}$ & $\begin{array}{c}-0.0227 * * * \\
(0.0032)\end{array}$ & $\begin{array}{c}-0.0210 * * * \\
(0.0024)\end{array}$ \\
\hline Metro & $\begin{array}{c}0.0049 * * * \\
(0.0006)\end{array}$ & $\begin{array}{c}0.0046^{* * * *} \\
(0.0009)\end{array}$ & $\begin{array}{c}0.0040 * * * \\
(0.0009)\end{array}$ & $\begin{array}{c}0.0045 * * * \\
(0.0008)\end{array}$ \\
\hline Rural & $\begin{array}{l}-0.0011 \\
(0.0007)\end{array}$ & $\begin{array}{l}-0.0009 \\
(0.0007)\end{array}$ & $\begin{array}{c}-0.0018 * * \\
(0.0007)\end{array}$ & $\begin{array}{l}-0.0010 \\
(0.0009)\end{array}$ \\
\hline dOilPrice*Coal0 & $\begin{array}{c}0.0063 * * * \\
(0.0011)\end{array}$ & $\begin{array}{c}0.0066^{* * * *} \\
(0.0012)\end{array}$ & $\begin{array}{c}0.0070 * * * \\
(0.0013)\end{array}$ & $\begin{array}{c}0.0064 * * * \\
(0.0012)\end{array}$ \\
\hline Coal0 & $\begin{array}{c}-0.0044 * * * \\
(0.0009)\end{array}$ & $\begin{array}{c}-0.0045^{* * * *} \\
(0.0013)\end{array}$ & $\begin{array}{c}-0.0035^{* *} \\
(0.0015)\end{array}$ & $\begin{array}{c}-0.0033 * * * \\
(0.0011)\end{array}$ \\
\hline \#Counties & 1069 & 409 & 250 & 420 \\
\hline sigma_u & 0.0023 & 0.0026 & 0.0033 & 0.0025 \\
\hline sigma_e & 0.0108 & 0.0102 & 0.0104 & 0.0100 \\
\hline rho & 0.0431 & 0.0592 & 0.0892 & 0.0577 \\
\hline \multicolumn{5}{|l|}{ R-Square } \\
\hline Within & 0.3050 & 0.3522 & 0.3133 & 0.3721 \\
\hline Between & 0.1021 & 0.0406 & 0.0793 & 0.1306 \\
\hline Overall & 0.3027 & 0.3374 & 0.2868 & 0.3504 \\
\hline
\end{tabular}

Robust standard errors in parenthesis.

* Significant at $10 \%$; ** significant at $5 \%$; *** significant at $1 \%$

Does our sample selection algorithm make any difference in the estimates? Somewhat surprisingly, given the clear endogeneity of the ARC's sample selection, the coefficient estimates for ARC, Core, Broad, and All county samples are of a similar magnitude. This similarity of results suggests that sample selection bias is not a large problem for this particular data set and model. The similarity of the standard errors across models, however, indicates possible excess heterogeneity in the ARC sample. Smaller data sets imply larger coefficient standard errors, which should increase according to the square root of the ratio of sample sizes. The Core Appalachian data set contains many fewer counties than the other three, (about 60 percent of the ARC and Broad samples, and 23 percent of the All sample). These sample size effects suggest that standard deviations of the Core estimates should be approximately 1.3 times those of the ARC estimates and twice those of the All sample estimates. Instead, the standard deviations of 
coefficients for the three sample sizes are of similar magnitude for most coefficients, consistent with our assertion that the Core data sets are more homogeneous.

To further explore this issue of the efficiency gain from using our method of selecting Appalachian counties we performed a bootstrap sampling experiment to see whether our Core sample's estimated standard errors are low by chance, or because the sample was well-chosen. ${ }^{7}$ In each of 10,000 bootstrap repetitions we drew randomly (with replacement) a sample of 250 counties from the set of 420 ARC counties. The sample size of 250 counties was chosen to reflect the number of counties in the Core Appalachian sample, so that the sample represented a Coresize sample of counties drawn at random from the population of ARC counties. In each case all four time-series observations were used from each county, so that the total size of the data set in each sample was $4 n=1000$. If the Core sample is no more homogeneous than the ARC sample, we would expect Core coefficient standard errors to rank at about the $50^{\text {th }}$ percentile of the standard errors from all the bootstrap samples. For each bootstrap repetition $b$ we applied our empirical model to the bootstrap sample to estimate the $k$-vector of regression coefficients $\hat{\beta}_{b}^{*}$ from that sample, along with its $k \times k$ coefficient covariance matrix $\operatorname{Cov}\left(\hat{\beta}_{b}^{*}\right)$. We then compared the size of $\operatorname{Cov}\left(\hat{\beta}_{b}^{*}\right)$ to the comparable covariance matrix obtained from our sample of 250 Core Appalachian counties $\operatorname{Cov}(\hat{\beta}$ core $)$. To do so, we calculated $\operatorname{Cov}\left(\hat{\beta}_{b}^{*}\right)-\operatorname{Cov}\left(\hat{\beta}_{\text {core }}\right)$ and tested to see if the result was positive definite, which would indicate that our Core sample's covariance matrix was smaller than the bootstrap sample's covariance. We found that our Core sample's covariance matrix was smaller than all but 12 percent of the bootstrap samples' covariance matrices drawn from the ARC counties, which indicates a high degree of uniformity of the Core sample relative to the ARC sample.

\subsection{Conclusions, Policy Implications, and Future Directions}

The empirical literature on the determinants of economic growth has long been impeded by problems of unobserved heterogeneity, multicollinearity, and endogeneity found in international data sets. The resource curse literature has exactly the same set of problems, and for the same reasons. The answers to many important questions are not identified in the data because we don't have enough exogenous structural variables or good instruments to control for all of the heterogeneity of the world's nations. For many years researchers in this area have sought to solve

\footnotetext{
${ }^{7}$ We thank an anonymous referee for suggesting the bootstrap experiment.
} 
the problem by using more sophisticated econometric methods and choosing instruments more cleverly.

We have addressed these problems by implementing a novel sample selection approach. Rather than trying to model and control for heterogeneity and endogeneity, we use exogenous criteria to construct a data set that minimizes heterogeneity. We have laid out the reasons why we regard the Appalachian region of the U.S. as a good candidate for this style of inquiry (uniform data collection, cultural homogeneity, balanced treatment design, and a set of questions that has attracted the keen interest of policy makers for half a century), and we have gathered a panel data set that has allowed us to isolate the presence of coal production as a source of exogenous variation. The results for our particular application suggest that any problems created by using the ARC definition of Appalachia for estimation of the resource curse arise more from the introduction of sampling noise rather than from bias due to endogenous sample selection. Partly, this result may be driven by the fact that few of the counties that are included in the ARC Appalachian sample but excluded from the Core Appalachian sample possess coal resources, meaning that heterogeneity in the economic growth variable in the excluded ARC counties arises from sources other than the resource abundance variable.

The lessons of this study are much clearer with respect to the possible efficiency gains from careful attention to sample selection. Our bootstrap experiment indicates that judicious use of exogenous cultural and geographical indicators to refine the sample selection algorithm can substantially reduce sampling variation, even within a sample such as the ARC counties that is already relatively homogeneous. It may be possible to improve upon the simple geographic contiguity and proximity measure used for sample selection by Michaels (2011), for example, if the researcher has sufficient knowledge of the region, creativity, and access to appropriate exogenous variables. Researchers seeking to study the impact of Marcellus Shale development may be able to apply some form of the sample selection algorithm developed here. Useful sample selection algorithms for studies of the Bakken or resources farther afield must be tailored to the characteristics of those regions, but this study may be of some use as an example of the kinds of variables to seek when developing such algorithms.

Although lagged income, rurality, topography, and location of mineral deposits are not endogenous, they are not policy variables either, which unfortunately limits the policy implications that may be drawn from our reduced-form empirical results. That does not mean that there are no policy implications of our analysis. Our results so far cast some doubt on the notion that encouraging coal extraction is tantamount to encouraging growth. They provide some 
support for those who suggest that well-considered regulatory impediments to unbridled coal extraction could actually encourage economic growth in the regions where the resources are found. This is a point that is not obvious to many policy makers, focused as they are on the benefits arising from exploitation of new sources of energy such as oil shale, tar sands, and shale gas. On the other hand, as Michaels (2011) demonstrated, those who assume that resource abundance and exploitation is always a curse may also be mistaken. Determining the conditions under which resource extraction may be conducted to the benefit of those who live where the resource is abundant is the task of social science researchers. The first step in getting clear answers from statistical analysis is to choose an appropriate sample that minimizes noise and bias. 


\section{Chapter 2 \\ An Analysis of Resource Curse Channels in the Appalachian Region}

\subsection{Introduction}

Evidence suggests that natural resource abundance can be either a curse or a blessing, but examples of countries that seem cursed by their resources are much more common. The "resource curse" refers to the widespread empirical finding that many areas rich in natural resources are cursed by lower income levels and slower economic growth. It can be described as a failure to capitalize on the potential growth opportunities presented by natural resources. The resource curse literature is extensive, and has investigated the channels or mechanisms through which natural resources tend to frustrate growth.

However, empirical work related to economic growth is notoriously susceptible to problems of endogeneity and omitted variables bias, and the resource curse literature is no exception. These issues are especially problematic when using international data sets, as is most often the case in the resource curse literature. Recently, a few studies have used sub-national level data (state, county, or municipality) to mitigate the statistical problems which arise from the inherent heterogeneity of international data. These include Papyrakis and Gerlagh (2007), which uses U.S. state level data; and Black, McKinnish, \& Sanders (2005a, 2005b), James and Aadland (2011), and Deaton and Niman (2012), which use U.S. county level data. In a recent survey article on the resource curse appearing in the Journal of Economic Literature, Frederick van der Ploeg (2011) put it this way:

Cross-country and panel-data results are sensitive to changing the sample period, the sample of countries, or the definition of various explanatory variables. The data may simply not allow one to distinguish, for example, whether it is openness to international trade, quality of institutions, or financial development since these variables are highly correlated. The road forward might be to exploit variation within a country where variables that might confound the relationship between resources and macroeconomic outcomes do not vary and the danger of spurious correlation is minimized. (JEL 49:2, p. 381).

I use the set of 409 broadly defined Appalachian counties as described in the first chapter, and in Douglas and Walker (2012). In this paper I use this relatively homogenous sample to empirically study the resource curse and its potential channels. By comparing counties in the region that have relatively large coal industries to counties that produce no coal, and controlling for other confounding factors which affect economic growth, I measure the effect of resource abundance on long run income growth using the natural experiment of variation in coal endowments in the Appalachia region. Using a more homogenous regional sample has several 
advantages: first, it mitigates problems related to omitted variable bias since counties of the same region of a nation likely have similar backgrounds, histories, and institutions that influence growth. There is less unobservable heterogeneity across counties of the same region than across different countries. Secondly, data quality and measurement error are common problems with cross country data, but data collected in the U.S. are generally considered more reliable and uniform. Lastly, counties do not have exchange rate variation, and there is little variation in the price level across the region.

The Appalachian region, in particular central Appalachia, has historically constituted one of the poorest regions of the United States. The poverty rate in Appalachia in 1965 was about 33\% compared to a national average of about 20\%. By 2008 the percentage of Appalachians living in poverty had dropped to $18 \%$, compared to the national average of approximately $13 \%$ (ARC). But these economic gains have not been distributed evenly across the region. In 2008, the Appalachian Regional Commission classified nearly 20 percent of counties in Appalachia (82 of 420 ) as "economically distressed." 8 The majority of these distressed counties lie in the central portion of the region, primarily in Kentucky and West Virginia, as shown in Appendix 3.

The Appalachian region is also rich in natural resources, especially coal. Coal production in the Appalachian region accounts for over one third of all coal produced annually in the United States (EIA). Coal production in West Virginia alone, which is the largest coal producing state in the region and the second largest in the nation, accounted for 13.5 percent of total U.S. coal production in 2008 (EIA 2009). Furthermore, the poorest areas within the Appalachian region are counties where coal mining dominates the local economy, as shown in Figure 2.1. A 'coal producing county' in this study denotes a county that produced coal during the initial year of the respective decade.

\footnotetext{
$8 \quad$ The Appalachian Regional Commission (ARC) was created in 1963 by President Kennedy (and enacted by Congress in 1965) in order to help spur economic growth in the region.
} 
Figure 2.1: Real per Capita Income, Coal versus Non-Coal Counties in Appalachia

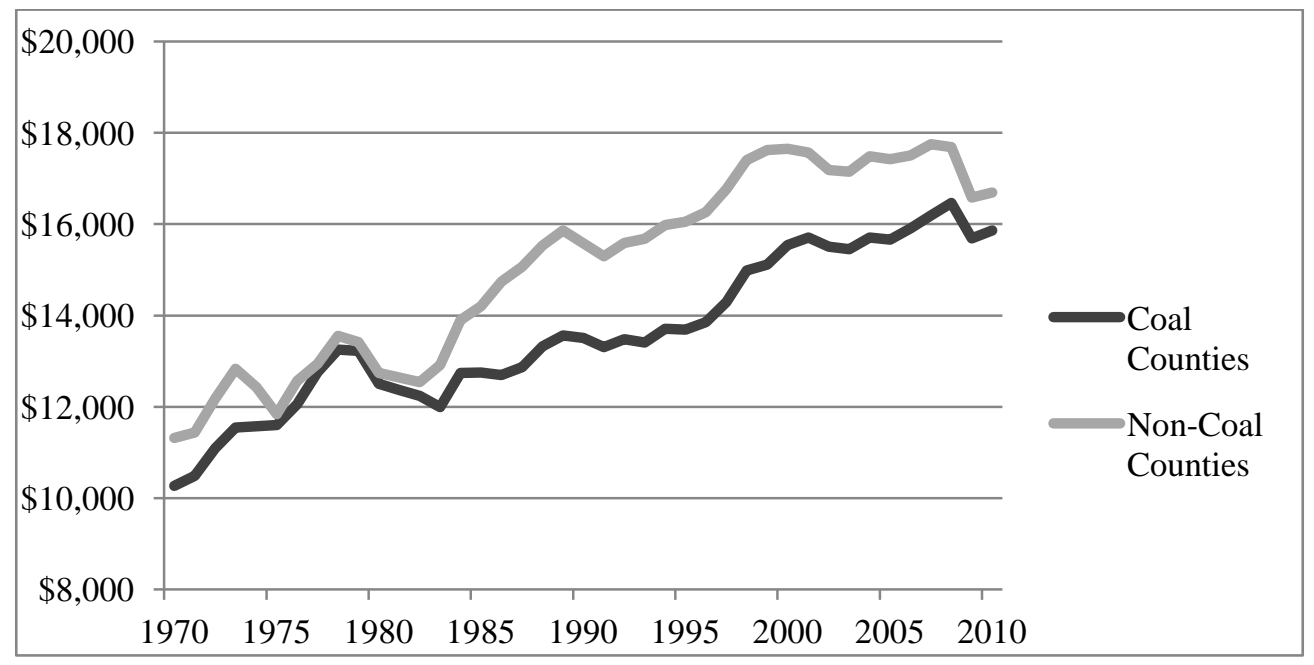

These observations naturally lead to the question of whether a resource curse exists in the Appalachian region. I investigate whether coal resource abundance negatively affects growth in the sample of Appalachian counties. I find evidence that coal abundance significantly reduces growth of per capita income over the long run. A one standard deviation increase in the resource abundance variable is associated with a reduction in average annual growth by an estimated 0.17 to 0.78 percentage points.

This paper makes several contributions to the resource curse literature. First, I am aware of no other published papers that study the resource curse in Appalachia by examining income growth over the long run. Most studies use poverty (Deaton and Niman, 2012; Partridge et al., 2012) or employment growth (Black et al., 2005b) Second, I use a carefully chosen sample of sub-national county level data to minimize unobservable heterogeneity across my sample, and therefore more precisely estimate the effect of resource abundance on growth. Third, I use instrumental variable techniques to account for the potential endogeneity of resource abundance measures and initial income. Lastly, I use multiple measures of resource abundance to verify the robustness of my results.

The remainder of this paper is organized as follows. Section 2.2 provides a brief overview of the resource curse literature. Section 2.3 defines the measures of resource abundance used in this study. Section 2.4 presents the empirical models, section 2.5 provides results of the estimations, and section 2.6 summarizes the conclusions and main results. 


\subsection{Brief Review of the Resource Curse Literature}

\subsubsection{Channels of the Resource Curse}

Theoretical arguments regarding the existence and magnitude of the resource curse have hypothesized several different mechanisms or "channels" through which the resource curse might operate. In general, the channels represent growth promoting activities that are somehow negatively affected by natural resource abundance. Much of the recent resource curse literature focuses on institutions as the primary mechanism through which resource abundance negatively affects growth. This is not surprising in light of the recent emphasis placed on institutions as a significant determinant in the more general economic growth literature (Acemoglu, Johnson, \& Robinson, 2001, 2002). Some studies view the resource curse as a result of resource abundance in the presence of pre-existing poor institutions. For example, Mehlum, Moene, \& Torvik (2006) maintains that institutional quality is decisive in how natural resource abundance affects economic growth, regardless of whether or not resource abundance affects institutional quality. However, most studies go one step further by claiming that resource abundance is a cause of poor institutional quality. Isham, Woolcock, Pritchett, \& Busby (2005), Bulte, Damania, \& Deacon (2005), Robinson, Torvik, \& Veridier (2006), and Collier (2010) conclude that resource wealth weakens the quality of institutions.

Poor institutional quality may appear in the forms of weak private property laws, rent seeking, corruption, conflict, low rates of entrepreneurship, poor governance, or low investment in growth-promoting activities. The latter two are discussed separately below. Many studies have found that the corrupting influence of resources on institutional quality and growth is especially strong in the case of point resources such as fuels and minerals, as opposed to nonpoint, diffuse resources such as agricultural products (Auty, 1997, 2001; Woolcock, Pritchett, \& Isham, 2001; Isham et al., 2005; Boschini, Pettersson, \& Roine, 2007). Collier (2010) concludes that resource revenue has a corrupting effect on institutions based on empirical evidence that democracy increases growth where natural resources are scarce, but has the opposite effect where they are abundant. This result is supported by studies such as Acemoglu, Robinson, \& Verdier (2003), which offers evidence that the high resource rents associated with natural resource endowments help dictators to maintain power. Natural resource abundance, as measured by the extent of primary commodity exports in a country, is correlated with an increased risk of conflict, again particularly in the case of point resources (Collier, 2010; Ross, 2004). Lastly, some studies find that entrepreneurial activities are crowded out both because of the wage premium and rent seeking opportunities provided by the natural resource sector (Sachs \& Warner, 2001). 
Second, a boom in the resource sector causes a persistent appreciation of both nominal and real exchange rates, causing the export sector to shrink, the "Dutch Disease" as described in Sachs \& Warner $(1995,1997$, and 2001). The appreciation of the real exchange rate creates several effects which result in the contraction of the export sector: It increases input prices for the export sector; and it makes exported goods relatively more expensive for foreign consumers. Van der Ploeg (2011) points out that the export sector also declines due to labor being drawn out of the sector and into the resource sector. To the extent that a resource windfall causes "Dutch Disease", and the exporting sector declines in employment, economic growth is hampered by a loss in learning by doing (van der Ploeg, 2011; Sachs \& Warner, 1995). This explanation relies on endogenous growth theories, and assumes that human capital spillover effects occur predominantly in exporting sectors.

Third, because young people have a disincentive to continue their education when relatively well-paying unskilled resource-sector employment opportunities are available, there is a negative correlation between resource dependence and school enrollment (Gylfason, Herbertsson, and Zoega, 1999, Gylfason, 2001; Black et al., 2005a; van der Ploeg 2011). Gylfason (2001) finds that expected years of schooling for girls and secondary school enrollment rates are both negatively related to the share of natural resource wealth across countries. Black et al. (2005a) focus on the effects of the coal boom of the late 1970s to early 1980s (and the subsequent bust) in Appalachia and find that high school enrollment rates declined substantially during the boom period and increased during the bust period. Papyrakis and Gerlagh (2007) find that schooling is the most important transmission channel in their resource curse study of the U.S. states.

\subsubsection{Resource Curse studies using sub-national data}

Very few previous studies have used sub-national data to address the resource curse question. Michaels (2011) uses county-level data to investigate the effect of oil resources on a variety of measures, including personal income and employment density, and devotes much attention to the problem of sample selection. In contrast to much of the rest of the empirical resource curse literature, he finds a positive effect of resource abundance on employment density and income growth, which he attributes to agglomeration economies. His paper is also of special interest here because he attempts to limit heterogeneity by drawing his sample only from counties within 200 miles of an oil resource.

James and Aadland (2011) found significant negative growth effects of resource abundance using a national cross section of 3092 counties over the 1980-1995 time period. Papyrakis and Gerlagh (2007) also found a resource curse using state-level U.S. data (specifically, they 
estimated that a one percent increase in resource abundance decreases growth by about .047 percentage points). These two studies use similar measures of resource abundance; James and Aadland (2011) use the percent of county earnings from agriculture, forestry, fishing, and mining, while Papyrakis and Gerlagh (2007) use the percent of gross state product from agriculture, forestry, fishing, and mining. There are also a few unpublished papers using sub-national data. They include dissertation chapters by Sen (2010), Corey (2008), and Dunn (2008), which employ U.S. data measured at the state and (in the case of Sen) county level. All of these studies analyze the United States as a whole and define resource abundance broadly, whereas I focus on Appalachia and coal in order to identify the mechanism sharply.

More recently, Marchand (2012) uses data from Western Canadian census divisions to investigate the impacts of the 1970's energy price boom and subsequent bust in 1980's, as well as the boom from 1996-2006 on employment and earnings. For the energy extraction industry, Marchand (2012) finds positive direct impacts of the boom periods and only modest negative effects from the bust period. In addition he finds positive spillover effects of the booms for nonenergy sectors, and divides non-energy sectors into "local goods" and "traded goods" to further analyze the effects of the booms and bust on employment and earnings. The local goods sector included construction, retail, and services, and Marchand estimated that for every 10 energy extraction jobs created, there were 3 construction jobs, 2 retail jobs, and 4.5 service jobs created, but that these sectors experienced a loss in earnings per worker during the bust. The traded goods sector was represented by manufacturing, and Marchand estimated positive effects on earnings not only from the boom (although smaller in magnitude than the effects on the local good sector), but also positive effects on earnings from the bust period as well.

Most recently, Caselli and Michaels (2013) looks at the effect of oil resources in different regions of Brazil, and finds that increased revenue to municipalities from oil windfalls do not translate into a significant increase in public good provision or the population's living standards. They also note the empirical advantages of using units of observations from within a country, and the resulting increase in the precision of estimates.

\subsubsection{Economic growth and natural resources in Appalachia}

Very few resource curse studies focus on the Appalachian region. Santopietro (2002) discusses the role of natural resources in growth, but mainly focuses on income convergence, comparing 127 central Appalachian counties to 152 non-central Appalachian counties in the same three states (Virginia, West Virginia, and Kentucky) between 1969 and 1997 using cross sectional methods. He tests for absolute convergence and finds that in terms of income levels, the central 
Appalachian counties are only barely converging with the rest of the region, at a very low rate of .03 percent per year. He argues that despite increases in productivity in coal mining during this time, natural resources have failed to help income levels in the region catch up to the surrounding area. Santopietro (2002) also does not attempt to explain the mechanism by which natural resources might have hindered income growth in Appalachia.

Deaton and Niman (2012) use county level panel data to examine poverty rates in Appalachia. They model poverty rates as a function of industry composition, measured as the percent of the population employed in various sectors (mining, manufacturing, agriculture, forestry, fisheries, construction, and services) and other controls. Their data set covers 399 Appalachian counties from 1960 to 1990, with three time periods each representing a decade. Deaton and Niman (2012) use county fixed-effect panel data estimation and find that an increase in the share of the population employed in the mining sector has an overall positive effect on the poverty rate. Like Santopietro (2002), they do not attempt to account for the channels through which heavy employment in mining may be positively affecting the poverty rate.

Black et al. (2005b) examine the effects of the coal market boom and bust during the late 1970s to early 1980s in Appalachia on both the locally traded goods sector, and on the nationally traded goods sector. They find evidence of spillover effects on employment in sectors with locally traded goods, but no evidence of any spillover effects in sectors with nationally traded goods. In the locally traded goods market, they find asymmetric effects of the boom and bust, estimating that for each 10 jobs added in the coal sector during the boom, fewer than two jobs were added in the local goods sector, but during the bust, for each 10 jobs lost in the coal sector, 3.5 jobs were lost in the local goods sectors.

Black et al. (2005a) study the effect of the same coal boom and bust on high school enrollment rates in Kentucky and Pennsylvania. They show that the boom in the late 1970s increased the earning of high school dropouts relative to those of graduates, and the bust decreased the earnings of dropouts relative to graduates. Black et al. (2005a) also find that as a result, high school enrollment rates declined considerably in the 1970s during the coal market boom, and increased in the mid to late 1980s in coal-producing counties relative to counties without coal. Their estimates imply that a ten percent increase in the earnings of low-skilled workers decreases high school enrollment rates by as much as five to seven percent, provided that the earnings increase is viewed as long term.

In an unpublished dissertation, Harkness (2010) studied the resource curse and several of its theoretical channels including taxation, public investment in education, and corruption using 
county-level data from Kentucky between 1980 and 2005. In cross sectional regressions, Harkenss found no connection between the slower growth experienced by coal dependent counties and a measure of coal abundance or of coal extraction. Harkness attributes the correlation between coal dependence and negative growth rates to geographical factors, such as geology and soil quality. Harkness (2010) also finds no support for the existence of an educational spending channel, a low-taxation channel, or a corruption channel. Aside from these few papers, no others have examined the potential causal mechanisms for a resource curse in the Appalachia region that I am aware of.

\subsection{Measuring natural resource abundance versus dependence}

There is some debate in the literature about how to best measure resource abundance. Several researchers have questioned the typically employed measures of resource abundance in cross-country studies, including both the primary exports divided by a measure of national income, and the share of resource industries in national income. Brunnschweiler (2008) cites several problems with export based measures, arguing that the existence of counter-examples of resource-rich countries such as Australia and Germany with relatively low proportions of primary exports indicate that natural resource abundance isn't necessarily correlated with the share of natural resource exports. Furthermore, she points out that it is possible for this measure to be biased due to reverse causation: a slow growth economy with a large share of natural recourse exports may result from poor policy.

Brunnschweiler (2008) also criticizes the use of production related data as a measure of resource abundance, arguing that it is potentially endogenous since production is likely affected by the differing levels of technology across countries. This is far less of a concern in the sample of 409 Appalachian counties given its relative cultural homogeneity. Brunnschweiler (2008), Brunnschweiler and Bulte (2008), and Stijins (2005) argue that natural resource wealth should be measured on a per capita basis, and claim that such a variable measures resource abundance rather than resource dependence. They advocate using World Bank indicators of per capita mineral wealth and per capita total natural resource wealth. ${ }^{9}$ Using these measures, Brunnschweiler (2008) finds a positive effect of natural resource abundance on growth across 84

\footnotetext{
$9 \quad$ The World Bank natural resource indicators value different components of natural wealth in U.S. Dollars per capita on the basis of the net present value of rents and are available for 1994 and 2000. Natural resources valued by the World Bank in both studies include subsoil assets (fuel and nonfuel minerals), timber resources, non-timber forest resources, protected areas, cropland, pastureland, and total natural capital.
} 
countries over the period 1970-2000, using OLS and 2SLS estimation methods on cross country data.

Brunnschweiler's positive result could be biased due to measurement error. Collier (2010) provides several persuasive reasons to believe that the quantity of subsoil assets in non-OECD countries is likely vastly underreported in World Bank data. First, if we assume that natural assets are randomly distributed geographically, then one would expect the law of large numbers to somewhat even out the distribution of natural assets across OECD and non-OECD countries. But according to the World Bank data, OECD countries have approximately four to five times more subsoil assets than most other non-OECD countries. Secondly, subsoil assets are likely understated in the non-OECD countries since there has been far less exploratory drilling there. And finally, non-OECD countries have shorter extraction histories, which combined with the notion that they should have roughly the same amount of subsoil assets as OECD countries, leads to the assumption that more assets should be left in the ground in non-OECD countries, contrary to World Bank data (Collier 2010). Another problem with using a per capita measure (if the aim is to measure 'resource abundance' over 'resource dependence') is that it is possible for large quantities of a resource to exist in a place that is sparsely populated.

Furthermore, many of the studies that have found positive or neutral effects of natural resources employ measures based on potential resource wealth (Brunnschweiler, 2008; Stijns, 2005). Papyrakis and Gerlagh (2007) note that most economists define resource abundance as proven reserves plus already exploited resources versus potentially exploitable resources, which may or may not become economically exploitable. The mere existence of resources in situ, or a pure abundance of resources, should affect growth mainly through the process of extraction, be those positive or negative effects. ${ }^{10}$ Therefore, it may be the case that resource dependence is of equal or greater importance than resource abundance when it comes to investigating the effects of resources on growth.

I employ both a measure of resource dependence and resource abundance to estimate the effect of resources on long run income growth. First, I use an indicator variable CoalO, equal to one if the county has ever produced any coal as of the initial year of the decade. This dummy variable is likely exogenous because the Appalachian coal fields are mature: nearly all of the counties, including all of the major coal producing counties, initiated coal production before out sample period. Only seven of 193 coal producing counties in the sample initiated production during the forty year period of study; in 1970, 186 counties had produced coal at some point in

10 Collier (2010) does however discuss problems related to the discovery process for natural resources. 
the past. By 1980, six new counties began production, bringing the total to 192. That number remained constant in 1990 and by 2000 only one additional county began producing coal, for a total of 193 coal producing counties. Because CoalO primarily indicates the exogenous geographic presence of commercially minable coal in a county, it more likely represents a measure of pure resource abundance as opposed to a measure of resource dependence. Table 1a shows the descriptive statistics for the CoalO variable.

\begin{tabular}{|c|c|c|c|c|c|}
\hline Year & Obs. & Mean & Std. Dev. & Min & Max \\
\hline 1970 & 409 & 0.45 & 0.50 & 0 & 1.00 \\
\hline 1980 & 409 & 0.47 & 0.50 & 0 & 1.00 \\
\hline 1990 & 409 & 0.47 & 0.50 & 0 & 1.00 \\
\hline 2000 & 409 & 0.47 & 0.50 & 0 & 1.00 \\
\hline
\end{tabular}

If the goal is to measure resource dependence on the other hand, then a measure that takes account of the size of the resource sector relative to the overall local economy is needed. The measure of resource dependence used here is $N R$, a continuous variable representing the ratio of resource revenue to pre-tax total personal income, net of government transfers. I measure its numerator, resource revenue, as the number of tons of coal produced in county $i$ during the initial year of the time period (in thousands), multiplied by the average real price of bituminous coal during the same year. Its denominator is total personal income for county $i$ during the same year, also in thousands. This measure mirrors the most typically employed measure used in the international resource curse literature, resource revenue as a share of gross domestic product. It addresses " "dependence" since it is a flow measure of the value of resources relative to the local economy. It is also a more appropriate measure than CoalO for capturing the effects of potential transmission channels, since the transmission mechanisms of the resource curse largely arise from a dependence on resources, versus the mere existence of resources is situ.

Table $1 \mathrm{~b}$ shows descriptive statistics for the natural resource abundance variable $(N R)$ for all 409 counties in the left panel, and for only coal producing counties in the right panel. "Coal producing counties" are defined as counties that produced a nonzero amount of coal during the initial year of the time period, $\left(N R_{i t} \neq 0\right)$ and all others are "non-coal counties." As shown in Table 1b, mean NR peaked in 1980 at 0.43 , and has declined since. In 1970 a total of 154 of the 409 counties in the sample (38\%) produced coal. By 1990, this number dropped to 145 counties ( $35 \%$ of the sample), and by 2000 , only 115 counties (28\%) were producing coal, reflecting increasing depletion of the Appalachian coal reserves in some counties. Although some counties 
in Appalachia are experiencing an irreversible decline in production, other counties are experiencing stable or increasing production (Milici \& Dennen 2009). ${ }^{11}$ In fact, 10 of these counties with stable or increasing production account for nearly half of all Appalachian coal produced in 2009. ${ }^{12}$

Table 2.2: Descriptive Statistics for NR (Coal Revenue as a Share of Personal Income) All Counties Coal Counties

\begin{tabular}{c|ccccc|ccccc} 
Year & Obs. & Mean & Std. Dev. & Min & Max & Obs. & Mean & Std. Dev. & Min & Max \\
\hline \hline 1970 & 409 & 0.09 & 0.24 & 0 & 2.10 & 154 & 0.23 & 0.36 & 0.0001 & 2.10 \\
1980 & 409 & 0.16 & 0.42 & 0 & 4.00 & 153 & 0.43 & 0.60 & 0.0002 & 4.00 \\
1990 & 409 & 0.12 & 0.38 & 0 & 3.17 & 145 & 0.35 & 0.57 & 0.0002 & 3.17 \\
2000 & 409 & 0.07 & 0.29 & 0 & 2.52 & 115 & 0.25 & 0.50 & 0.00001 & 2.52 \\
\hline \hline
\end{tabular}

\subsection{Data and Empirical Models}

Per capita income growth differs substantially between coal and non-coal producing counties, and the relative performance of each group is associated with boom and bust cycles in energy markets (as shown in Figures 2.2 and 2.3). During the energy boom of the mid to late 1970 's, coal counties had an average growth rate about three quarters of a percentage point higher than non-coal counties. During the energy bust and the industry retooling of the 1980's, the trend more than reversed, with non-coal counties outperforming coal counties by about one and a third percentage points. The 1990's brought broad but moderate growth to both coal and non-coal counties. During the most recent time period, which includes an energy boom beginning in 2004, coal counties have once again outperformed non-coal counties, by 0.70 percentage points annually, on average.

Figure 2.2 illustrates the inverse correlation between the real price of bituminous coal and the difference between mean incomes levels for coal producing counties and non-coal producing counties. The higher the price of coal, the higher is per capita income in coal producing counties relative to non-coal producing counties. Figure 2.2 also shows the spike in coal prices in the mid to late 1970's, and the more recent rise in coal prices beginning in 2004.

\footnotetext{
11 Fourteen counties that are in irreversible decline include Fayette WV, Harrison WV, Marion WV, McDowell WV, Raleigh WV, Wyoming WV, Alleghany PA, Cambria PA, Clearfield PA, Fayette PA, Indiana PA, Somerset PA, Washington PA, and Westmoreland PA (Milici and Dennen 2009).

12 Ten counties that yielded nearly half of all Appalachian coal produced in 2009 are Boone, WV, Kanawha WV, Logan WV, Mingo WV, Monongalia WV, Buchanan VA, Wise VA, Perry KY, Pike KY, and Greene PA (Milici and Dennen 2009).
} 
Figure 2.2: Real Price of Bituminous Coal and Mean Growth of Real Per Capita Personal Income of Coal and Non-Coal Appalachian Counties

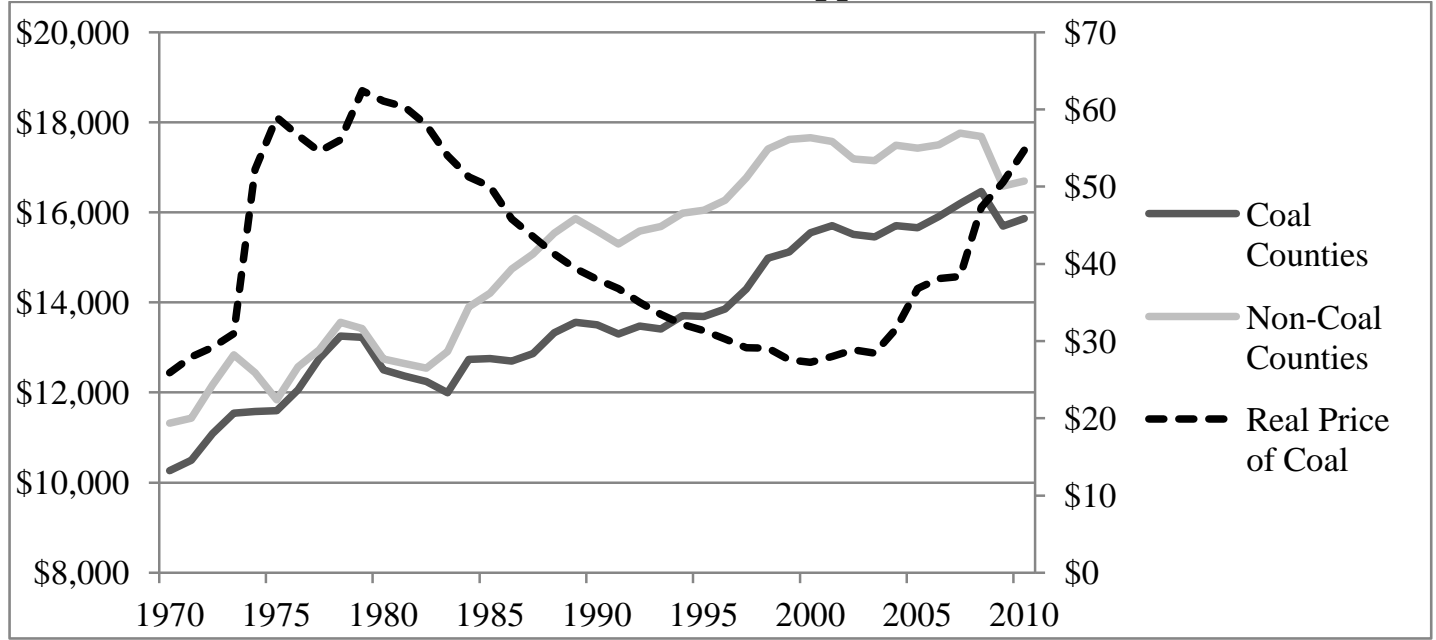

Source: EIA, BEA, Author's calculations

Figure 2.3: Mean Growth of Per Capita Personal Income of Coal and Non-Coal Appalachian Counties

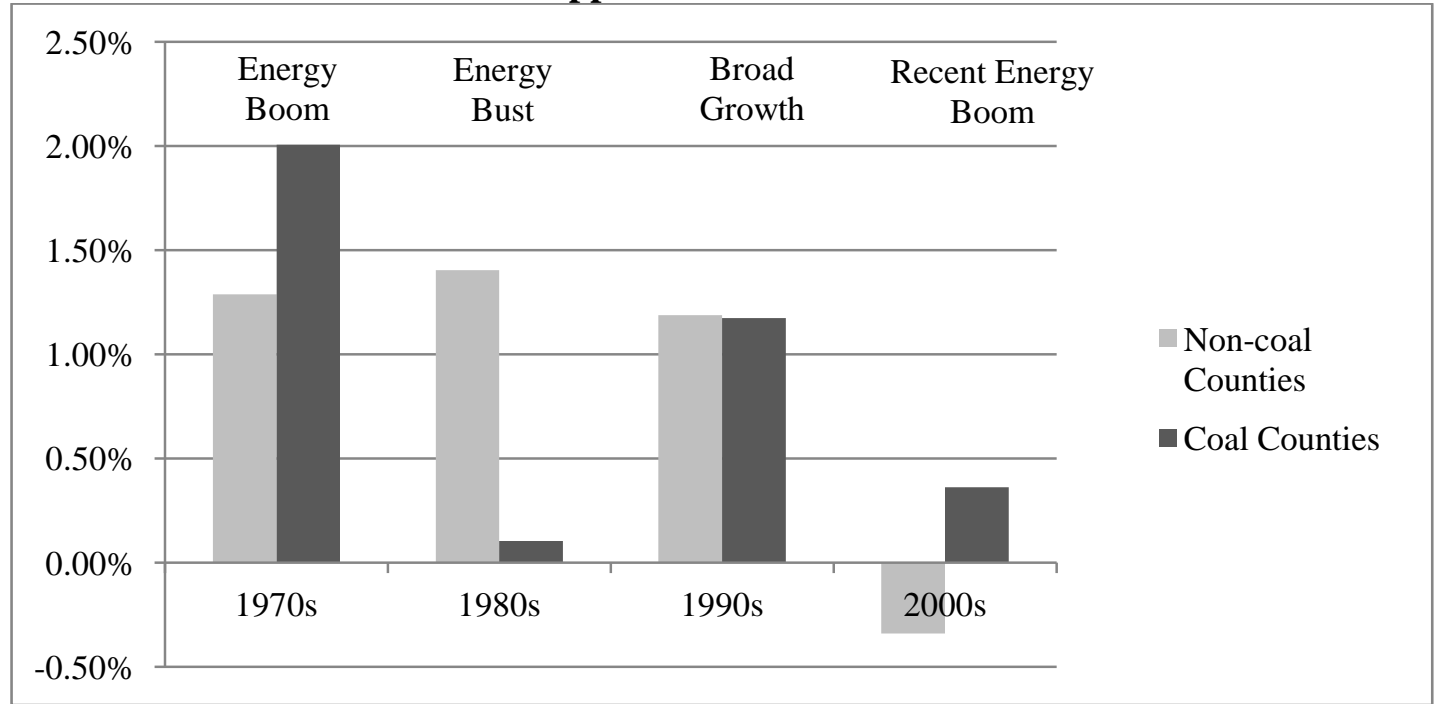

Source: BEA, Author's calculations

I first specify a panel model that checks for evidence of an effect of coal resources on income growth in the sample of 409 Appalachian counties, comparing coal dependent and noncoal dependent counties. I first use the CoalO variable discussed in section four as a measure of resource abundance as follows:

$$
g_{i t}=\beta_{1} \operatorname{Ln} Y_{i t}+\beta_{2} \operatorname{Coal0}_{i t}+\beta_{3} X_{i t}+\beta_{4} Y r_{t}+\mu_{s}+u_{i t}
$$

The model has four time periods which are each ten years long (1970-1980, 1980-1990, 19902000, and 2000-2010). The dependent variable is the average long-run growth rate $\left(g_{i t}\right)$, measured as the difference in log per capita personal income $\left(\operatorname{Ln} Y_{i t}\right)$ divided by the length of the 
period which is 10 years, or $g_{i t}=\left(\frac{1}{10}\right)\left(\operatorname{Ln} Y_{i t+10}-\operatorname{Ln} Y_{i t}\right)$ for county $i$ in state $s$ at time $t$. Personal income is measured pre-tax and net of government transfers. The use of these specific time periods has several advantages. First, they roughly coincide with the timing of recent boom and bust cycles in oil and other energy markets. Second, these time periods allow for variables from decennial censuses to be used as controls.

The explanatory variable of interest in equation (2a) is Coal $_{i t}$, a dummy variable equal to one if the county ever produced coal at any point in the past, as of the initial year of the time period. The CoalO variable is exogenous since is represents the geographic presence or absence of commercially minable coal in a county, and therefore I use OLS to estimate equation (2a). I test the null hypothesis that resource abundance has no significant effect on income growth $\left(H_{o}: \beta_{2} \geq\right.$ 0 ) against the alternative hypothesis that resource abundance negatively affects growth $\left(H_{A}: \beta_{2}<\right.$ 0 ). Rejection of the null hypothesis is evidence that resource abundance acts as a curse against growth in the sample of Appalachian counties, ceteris paraibus. Descriptive statistics for CoalO are shown in Table 1a.

Following the economic growth and convergence literature (Temple 1999), I model the average long-run growth rate of per capita income as a function of log real per capita personal income during the initial year of each time period, $\left(\operatorname{Ln} Y_{i t}\right)$. A significantly negative coefficient on this term implies conditional convergence of incomes, or that counties with lower per capita incomes will grow faster, catching up to counties with higher incomes over time. Evidence for convergence across U.S. counties is provided by Rappaport (1999), Higgins et al. (2006), and Young et al. (2008).

The vector of control variables in equation (2a), $X_{i t}$, includes three additional conditioning variables, two of which are dummy variables that control for rural isolation as well as urban stimulation. These variables were derived from the USDA's Rural-Urban Continuum ("Beale") Codes, as shown in Appendix 6. Beale Codes are available for 1974, 1983, 1993, and 2003, and are based primarily on data from the previous census, so I treat them as exogenous beginning-ofperiod values for their respective decades. Because they are non-monotonic, I use them to create rural and metro dummy variables (Rural, Metro). Given the location of the poorest counties in very rural areas, and the difficulties that geographical isolation makes for growth and commerce, I expect positive coefficients for metro area indicators and negative coefficients for rural indicators. The time fixed effects vector $Y r_{t}$ consists of $T$-1 dummy variables indicating the time period. Their inclusion is standard in panel growth models, as they essentially transform each 
variable into a difference from its cross-sectional mean as of time $t$. Inclusion of these time fixed effects controls for the business cycle and other shocks common to all counties at a given time.

The third variable in $X_{i t}$ is an interaction variable between the percent change in oil price over the time period, (dOil Price), and a dummy variable equal to one if county $i$ produced coal during the initial year of the time period (NRdum). This variable controls for the cyclical effects of boom and bust cycles due to price shocks in oil markets that have special effects on coal producing economies (Engemann, Owyang, \& Wall, 2011). Since World War II these boom and bust cycles have been driven by changes in energy prices, which can be measured by changes in oil prices. Inclusion of this term allows the coefficient on the variable representing resource abundance to capture the non-cyclical, long-run effect of natural resource abundance.

Equation (2a) contains a state fixed effect term, $\mu_{s}$, which accounts for state-specific effects on the county's growth rate. These include characteristics such as income, severance, sales, and inheritance taxes, broad infrastructure and educational policy, the structure of the judicial system, much law enforcement (including environmental law enforcement), and corruption which are all strongly affected by statewide institutions. A Hausman test ruled out the random effects model for all specifications.

Next, I specify a panel model identical to equation (2a), but I instead use the $N R$ variable discussed in section four to capture the effects of coal resources on the local economy:

$$
g_{i t}=\beta_{1} L n Y_{i t}+\beta_{2} N R_{i t}+\beta_{3} X_{i t}+\beta_{4} Y r_{t}+\mu_{s}+u_{i t}
$$

The $N R$ variable constitutes a measure of resource dependence, or the size of the resource sector relative to the local economy. It is the ratio of resource revenue to total personal income in county $i$ during the initial year of the period, where resource revenue is estimated as the price of coal in year $t$ multiplied by the number of thousands of tons of coal produced in county $i$ during year $t$. I set the $N R$ variable to the initial year of each time period to help mitigate endogeneity, as is standard in growth literature. I test the null hypothesis that resource abundance has no significant effect on income growth $\left(H_{o}: \beta_{2} \geq 0\right)$ against the alternative hypothesis that resource abundance negatively affects growth $\left(H_{A}: \beta_{2}<0\right)$. Rejection of the null hypothesis is evidence that coal resource dependence acts as a curse against growth in the sample of Appalachian counties, ceteris paraibus. The descriptive statistics for $N R$ are shown in Table $1 b$.

The choice of estimation method for the growth regression equation (2b) depends on whether or not the $N R$ variable can be treated as exogenous. As Brunnschweiler (2008) points out, researchers often consider it to be exogenous despite reasons to believe otherwise. The 
numerator is a flow regressor, and is therefore likely to be simultaneously determined by economic growth (Caselli, Esquivel, \& Lefort, 1996). The denominator, total personal income of the county during the initial year, may also be endogenous given that the dependent variable is growth in personal income. Testing confirms that the $N R$ variable should be considered as endogenous in equation ( $2 b$ ), therefore I estimate the model with two-stage least squares (2SLS) in addition to OLS.

The 2SLS method is consistent, given that the required conditions regarding the selection of instrumental variables are satisfied. I attempt to isolate the exogenous component of $N R$ with two instrumental variables. The first is the CoalO dummy variable previously described. It is equal to one if the county has ever produced any coal as of the initial year of the time period, thus indicating the presence or absence of commercially minable coal in a county. Therefore, the CoalO variable should only affect income growth through current and recent extraction, making it a valid instrument for $N R$. The $N R$ and CoalO variables are also highly correlated, making CoalO a strong instrument as well.

The second instrument I use for the $N R$ variable is SlavePct1860, a continuous variable indicating the percent of the population that were slaves in 1860. SlavePct1860 is a valid instrument since it is clearly predetermined relative to income growth from 1970 to 2010. SlavePct1860 could conceivably be correlated with the accumulation of assets over time resulting in higher income, but this is controlled for by the initial income variable. In addition, the homogeneity of the sample mitigates the possibility of SlavePct1860 being correlated with omitted variables affecting growth. The SlavePct1860 variable is also inversely correlated with the $N R$ variable, as counties with more mining tend to be located in areas with more rugged landscapes, where plantations and slavery were uncommon.

Lastly, there is also a concern over the endogeneity of the initial income variable, $\operatorname{Ln} Y_{i t}$. Initial income may be correlated with the $N R$ measure of resource dependence through the denominator of $N R$, and therefore the estimation method should account for this possible endogeneity to obtain an unbiased estimate of the effect of $N R$ on income growth. Therefore, the initial income variable will be instrumented with lagged initial income. The method of using lagged values for instruments for right-hand-side variables in growth regressions is a widely used practice in the economic growth literature; see Arellano Bond (1991) for example.

In summary, I estimate the panel growth model with a measure of resource abundance, Coal0, represented by equation (2a), using OLS. I next estimate the panel growth model with a measure of resource dependence, $N R$, represented by equation (2b), using both OLS and 2SLS. I 
conduct an additional 2SLS estimation using equation (2b) taking into account the possible endogeneity of initial income. Lastly, I perform the estimations using a variety of alternative measures of resource abundance (shown in Table 2.7) to confirm the robustness of the results. Testing indicates the presence of heteroskedasticity so all estimations are performed with robust standard errors. Table 2.3 contains variable descriptions and data sources, and Table 2.4 contains descriptive statistics for all variables and instruments used in the study. All control variables are set to the initial year of the time period. All prices are measured in constant year 2000 dollars.

\section{Table 2.3: Variable Descriptions and Sources}

\begin{tabular}{llc} 
Variable & Description & Source \\
\hline \hline git & Average annual growth of real per capita person income & BEA \\
LnY(it) & Beginning of period real per capita personal income & BEA \\
Metro County & $=1$ if Beale code $\leq 3$ (Metro area) & USDA \\
Rural County & $=1$ if Beale code $\geq 7$ (Very rural, or population $<20,000$, & USDA \\
not adjacent to an urban county) & EIA, USGS \\
NRDum & $=1$ if $N R \neq 0,=0$ if $N R=0$. & EIA, USGS \\
(dOil Price $)^{*}($ NRDum $)$ & $\begin{array}{l}\text { Interaction variable between the percent change in real oil } \\
\text { price over the time period, and NRDum indicator variable } \\
\text { CoalO }\end{array}$ & EI if county has ever produced coal as of initial year of \\
period & Coal revenue (price*production) divided by total county \\
personal income, during initial year of period & EIA, USGS \\
Year $X X X X$ & $\begin{array}{l}\text { Year fixed effect } \\
\text { Percentage of population that were slaves according to } 1860\end{array}$ & Census \\
\hline \hline
\end{tabular}

Table 2.4: Descriptive Statistics

\begin{tabular}{lccccc} 
Variable & Obs & Mean & Std. Dev. & Min & Max \\
\hline \hline git & 1636 & 0.009 & 0.013 & -0.045 & 0.093 \\
LnY(it) & 1636 & 9.493 & 0.304 & 8.322 & 10.463 \\
Metro County & 1636 & 0.269 & 0.444 & 0 & 1 \\
Rural County & 1636 & 0.438 & 0.496 & 0 & 1 \\
NRDum & 1636 & 0.347 & 0.476 & 0 & 1 \\
(dOil Price)*(NRDum) & 1636 & 0.127 & 0.626 & -0.940 & 1.650 \\
CoalO & 1636 & 0.466 & 0.499 & 0 & 1 \\
NR & 1636 & 0.110 & 0.342 & 0 & 3.997 \\
SlavePct1860 & 1636 & 6.781 & 7.901 & 0 & 43.900 \\
\hline \hline
\end{tabular}




\subsection{Results}

Table 2.5 shows the results of estimating equation (2a) on the sample of 409 Appalachian counties. All estimations included state-level fixed effects and robust standard errors. The estimated coefficient on the CoalO variable is negative and statistically significant at the 5\% level, and equals -0.0040 . This estimate implies that the presence of commercially minable coal is associated with a reduction in average annual growth of about 0.40 percentage points.

Table 2.5: Estimates of the effect of Coal Abundance on Economic Growth (Equation 2a) Dependent Variable: Average Annual Growth in Real Per Capita Personal Income 1970-2010 Sample Size: $\mathrm{T}=4$ (1970-2010), N=409 Counties, total obs. $=1636$

(1a)

\begin{tabular}{|c|c|}
\hline & OLS FE \\
\hline $\operatorname{LnY}(i t-\tau)$ & $\begin{array}{c}-0.0194 * * * \\
(0.0018)\end{array}$ \\
\hline Metro County & $\begin{array}{c}0.0048 * * * \\
(0.0009)\end{array}$ \\
\hline Rural County & $\begin{array}{c}-0.0008 \\
(0.0006)\end{array}$ \\
\hline Year 1970 & $\begin{array}{c}0.0067 * * \\
(0.0028)\end{array}$ \\
\hline Year 1980 & $\begin{array}{c}0.0099 * * * \\
(0.0025)\end{array}$ \\
\hline Year 1990 & $\begin{array}{c}0.0133 * * * \\
\quad(0.0024)\end{array}$ \\
\hline dOilPrice*NRDum & $\begin{array}{c}0.0070 * * * \\
(0.0016)\end{array}$ \\
\hline Coal0 & $\begin{array}{c}-0.0040 * * \\
(0.0013)\end{array}$ \\
\hline Constant & $\begin{array}{c}0.1852 * * * \\
(0.0177)\end{array}$ \\
\hline Observations & 1636 \\
\hline R-squared & 0.41 \\
\hline
\end{tabular}

$\overline{\text { Robust standard errors in parenthesis. }}$

* Significant at $10 \%$; * significant at 5\%; *** significant at $1 \%$

Over time, even small decreases in average annual income growth have a substantial impact on income levels. For example, a drop in average annual income growth of 0.40 percentage points results in income levels being lowered by about 17 percent over forty years, with compounding. Therefore, when comparing two Appalachian counties with a one unit difference in the resource abundance measure (but similar in other ways), one would expect that the county 
with fewer resources would have experienced faster income growth and be about 17 percent richer over a forty year period, had it begun with a similar per capita income level.

The potential difference in long run income levels can be illustrated with an example using two counties: Monroe County West Virginia, a county with no coal, and Buchanan County Virginia, a county that has been moderately reliant on coal mining throughout the study period. (Throughout the study period, Monroe had a $N R$ value of 0 while Buchanan has an $N R$ value of approximately 1.) Monroe County began the 40 year study period in 1970 with a per capita income level about eighteen percent lower than that of Buchanan County. But due to faster income growth in Monroe County over the long run, by the year 2000 Monroe County had an income level nearly six percent higher than that of Buchanan County. After the most recent boom in coal prices from that began in 2004, income in Monroe County was one again lower than income in Buchanan County in 2010, but only by about seven percent. Despite the recent boom in coal prices, Monroe was able to make much larger gains in income levels over the long run; it began with income levels far below Buchanan, and ended up with an income level much closer to Buchanan.

Table 2.6 shows the results of estimating equation (2b) on the sample of 409 Appalachian counties. All estimations included state-level fixed effects and robust standard errors. The estimated coefficient on the $N R$ variable is negative and statistically significant at the $1 \%$ level for all estimations, and ranges from -0.0034 (OLS) to -0.0157 (2SLS). The OLS estimates imply that a one unit increase in resource dependence results in a reduction in average annual growth of about 0.34 percentage points, while the 2 SLS estimate implies a larger reduction of approximately 1.5 percentage points. A one unit increase in the resource variable represents is a relatively large increase in the $N R$ measure; resource revenue relative to total personal income must double in order for the $N R$ variable to increase by one unit. It is therefore more logical to discuss the effect of a one standard deviation change in the $N R$ variable, which is 0.50 for the coal producing counties in 2000. A one standard deviation increase in the $N R$ variable yields a reduction in average annual growth by an estimated 0.17 percentage points using the OLS estimate, and by an estimated 0.78 percentage points according to the 2SLS estimate with only $N R$ as endogenous. However, when the endogeneity of initial income $(\operatorname{Ln} Y)$ is also taken into account, the estimated coefficient on $N R$ drops to -0.0086 but remains highly significant. According to this estimate, a one standard deviation increase in resource dependence reduces average annual growth by an estimated 0.43 percentage points. 
Both the Hausman test and the endogeneity test indicate that the $N R$ and the initial income variables should be treated as endogenous. The variables CoalO and SlavePct1860 were used as instruments for the $N R$ variable in the 2SLS estimations in columns (2) and (3), and lagged initial income $\left(\operatorname{Ln} Y_{i t-10}\right)$ was used as an instrument for initial income $\left(\operatorname{Ln} Y_{i t}\right)$ in column (3). If the equation is overidentified, (as is the case here since there are two endogenous variables and three excluded instrumental variables) then the second assumption, that the instruments are uncorrelated with the residual, can be tested. The null hypothesis of the Hansen J test is that the excluded instrumental variables are valid, or uncorrelated with the error term in equation ( $2 b$ ).

As shown in Table 2.6, the p-value of the Hansen J test statistic for each of the 2SLS estimations in columns (2) and (3) indicate a failure to reject the null hypothesis of joint instrument validity.

Table 2.6: Estimates of the effect of Coal Dependence on Economic Growth (Equation 2b) Dependent Variable: Average Annual Growth in Real Per Capita Personal Income 1970-2010 Sample Size: $\mathrm{T}=4$ (1970-2010), N=409 Counties, total obs. $=1636$

\begin{tabular}{|c|c|c|c|}
\hline & $\begin{array}{c}(1 \mathrm{~b}) \\
\text { OLS FE }\end{array}$ & $\begin{array}{c}\text { (1b) } \\
\text { 2SLS (NR } \\
\text { endogenous) }\end{array}$ & $\begin{array}{c}(1 \mathrm{~b}) \\
\text { 2SLS (NR, } \operatorname{LnY} \\
\text { endogenous) }\end{array}$ \\
\hline LnY(it) & $\begin{array}{c}-0.0177 * * * \\
(0.0010)\end{array}$ & $\begin{array}{c}-0.0188 * * * \\
(0.0018)\end{array}$ & $\begin{array}{c}-0.0096 * * * \\
(0.0023)\end{array}$ \\
\hline Metro County & $\begin{array}{c}0.0045 * * * \\
(0.0007)\end{array}$ & $\begin{array}{c}0.0040 * * * \\
(0.0007)\end{array}$ & $\begin{array}{c}0.0032 * * * \\
(0.0007)\end{array}$ \\
\hline Rural County & $\begin{array}{r}-0.0005 \\
(0.0006)\end{array}$ & $\begin{array}{r}-0.0002 \\
(0.0007)\end{array}$ & $\begin{array}{l}0.0007 \\
(0.0008)\end{array}$ \\
\hline Year 1970 & $\begin{array}{c}0.0077 * * \\
(0.0028)\end{array}$ & $\begin{array}{c}0.0072 * * * \\
(0.0011)\end{array}$ & \\
\hline Year 1980 & $\begin{array}{c}0.0103 * * * \\
(0.0026)\end{array}$ & $\begin{array}{c}0.0110 * * * \\
(0.0009)\end{array}$ & $\begin{array}{c}0.0144 * * * \\
(0.0010)\end{array}$ \\
\hline Year 1990 & $\begin{array}{c}0.0134 * * * \\
(0.0025)\end{array}$ & $\begin{array}{c}0.0139 * * * \\
(0.0008)\end{array}$ & $\begin{array}{c}0.0154 * * * \\
(0.0007)\end{array}$ \\
\hline doilprice*NRdum & $\begin{array}{c}0.0064 * * * \\
(0.0015)\end{array}$ & $\begin{array}{c}0.0065 * * * \\
(0.0006)\end{array}$ & $\begin{array}{c}0.0091 * * * \\
(0.0009)\end{array}$ \\
\hline NR & $\begin{array}{c}-0.0034 * * * \\
(0.0008)\end{array}$ & $\begin{array}{c}-0.0157 * * * \\
(0.0026)\end{array}$ & $\begin{array}{c}-0.0086 * * * \\
(0.0028)\end{array}$ \\
\hline Constant & $\begin{array}{c}0.1676 * * * \\
(0.0099)\end{array}$ & & \\
\hline Observations & 1636 & 1636 & 1227 \\
\hline R-squared & 0.40 & - & - \\
\hline $\begin{array}{l}\text { Hansen } \mathrm{J} \text { test } \\
(P \text {-Value })\end{array}$ & $\begin{array}{l}- \\
-\end{array}$ & $\begin{array}{c}0.986 \\
(0.3208)\end{array}$ & $\begin{array}{c}0.688 \\
(0.4070)\end{array}$ \\
\hline
\end{tabular}

Robust standard errors in parenthesis.

* Significant at $10 \%$;* significant at $5 \%$; *** significant at $1 \%$ 
I test the first assumption, that the instruments are correlated with the endogenous variable, using the Angrist-Pischke F test. The null hypothesis of the Angrist-Pischke F test is that the endogenous variable is unidentified by the instruments. For the estimation in column (2) of Table 2.6 with only $N R$ treated as endogenous, the Angrist-Pischke F statistic is 71.53 and significant at the one percent level, indicating a rejection of the null hypothesis. For the estimation in column (3) with both $N R$ and $\operatorname{LnY}$ treated as endogenous, the Angrist-Pischke F statistic for the first stage estimation of $N R$ is 51.48 and significant at the one percent level. The Angrist-Pischke F statistic for the first stage estimation of $\operatorname{LnY}$ is 717.04 is also significant at the one percent level, also indicating a rejection of the null hypothesis. In addition, each instrument is significantly correlated with its respective endogenous variable, and of the expected sign in the first stage results.

The convergence hypothesis implies that a county with a lower level of initial per capita income will catch up to richer counties that have similar characteristics over time. Consistent with a wide literature supporting conditional convergence of per capita income, the estimated coefficients on the log of initial per capita income are negative and significant at the $1 \%$ level in each specification in tables 5 and 6. Following Higgins et al. (2006), the implied asymptotic rate of convergence $(r)$ can be inferred from the coefficient for initial income using the formula $r=$ $1+\left(1-T \beta_{1}\right)^{1 / T}$. The estimated coefficient on the initial income variable when it is considered as exogenous is -0.0188 , as shown in column (2). But when initial income is considered endogenously and instrumented, the estimated coefficient decreases to -0.0096 , as shown in column (3). This makes little difference however in the calculation of the rate of conditional income convergence; it goes from $2.02 \%$ for the estimation in column (2) to $2.01 \%$ for the estimation in column (3). These estimates imply that counties close the gap between their steady state balanced growth path and their initial level of income at a speed of 2.01 to 2.02 percent annually, all else equal. This concurs with the typically reported $2 \%$ rate, and but is substantially lower than the rate of 6-8\% found in Higgins et al. (2006) for all U.S. counties. Higgins et al. (2006) did not measure convergence for the Appalachian region, but they did measure it for the southern states and estimated a rate of $11.49 \%$.

The estimated coefficients for the metro dummy were all positive and significant at the one percent level, as predicted, while the rural dummy variable was not significant in any of the specifications. This implies that economies of agglomeration in urban areas positively influence income growth, while rural surroundings neither help nor inhibit income growth. The year fixed effects were all significant at the one percent level in the 2SLS regressions, signifying the 
presence of common period effects in real income growth. The estimated coefficients for the interaction variable between the current coal production dummy and the change in oil price were also positive and significant at the one percent level in each regression, which implies that changes in the price of oil have a positive effect on income in coal producing areas.

I used several alternative measures of resource intensity to test the robustness of the results. These measures are defined in Table 2.7, and their descriptive statistics are shown in Table 2.8. I used each of these variables in the growth regression and repeated the estimation using both OLS and 2SLS with the resource measure as endogenous. The resulting estimates are shown in Table 2.9. The results are robust to any of the alternative measures. For example, following James and Aadland (2011), I measure resource abundance as the share of total earnings in agriculture, forestry, fishing, and mining, and find a negative and significant coefficient of -0.0352 , using 2SLS. Per capita based measures of resource intensity, such as coal revenue divided by population (NR2), coal production divided by population (NR5), and cumulative coal production divided by population (NR7) all yield negative and statistically significant and economically significant coefficients. As previously stated, some researchers argue for the use of per capita measures, but here the distinction makes no difference to the qualitative results. Area may be an alternative way to exogenously scale the measure of resource intensity. Coal revenue divided by area (NR3), coal production divided by area (NR6), and cumulative coal production divided by area $(N R 8)$ all yield negative and statistically significant coefficients as well.

Table 2.7: Alternative Measure of Coal Abundance

Variable

AFFM_Share

NR2 $=($ Price*Prod $) /$ Pop

NR3 $=($ Price $*$ Prod $) /$ Area

NR4 $=($ Prod $) /$ PI

NR5 $=($ Prod $) /$ Pop

NR6 $=($ Prod $) /$ Area

NR7=(Cumul.Prod)/Pop

NR8 $=$ (Cumul.Prod)/Area

\section{Description}

Earnings from agriculture, forestry, fishing, and mining divided by total earnings

Coal revenue (price* production) divided by total county population Coal revenue (price* production) divided by total county area (square $\mathrm{km}$.)

Coal production divided by total county personal income

Coal production divided by total county population

Coal production divided by total county area

Cumulative coal production divided by total county population

Cumulative coal production divided by total county area

* All variables measured during initial year of period 
Table 2.8: Descriptive Statistics for Alternative Measure of Coal Abundance

\begin{tabular}{lccccc} 
Variable & Obs & Mean & Std. Dev. & Min & Max \\
\hline \hline AFFM_Share & 3325 & 0.036 & 0.085 & 0 & 0.856 \\
NR2=(Price*Prod)/Pop & 4276 & 0.525 & 2.694 & 0 & 58.1 \\
NR3=(Price*Prod)/Area & 4276 & 14.1 & 69.4 & 0 & 1351.8 \\
NR4=(Prod)/PI & 4276 & 0.001 & 0.006 & 0 & 0.093 \\
NR5=(Prod)/Pop & 4276 & 0.014 & 0.071 & 0 & 1.250 \\
NR6=(Prod)/Area & 4276 & 0.367 & 1.780 & 0 & 28.610 \\
NR7=(Cumul.Prod)/Pop & 4276 & 0.694 & 3.067 & 0 & 48.537 \\
NR8=(Cumul.Prod)/Area & 4276 & 21.1 & 90.5 & 0 & 1137.2 \\
\hline \hline
\end{tabular}

Table 2.9: Estimates of the effect of Coal Dependence on Economic Growth using Alternative Measures of Coal Abundance

Dependent Variable: Average Annual Growth in Real Per Capita Personal Income 1970-2010 Sample Size: $\mathrm{T}=4$ (1970-2010), N=409 Counties, total obs. $=1636$

\begin{tabular}{lcc}
\hline & $(1 \mathrm{~b})$ & $(1 \mathrm{~b})$ \\
& OLS FE & 2SLS $(N R$ endog $)$ \\
\hline AFFM_Share & $-0.0157^{* * *}$ & $-0.0352^{* * *}$ \\
NR2=(Price*Prod)/Pop & $-0.0003^{* * *}$ & $-0.0013^{* * *}$ \\
NR3=(Price*Prod)/Area & $-0.00001^{* *}$ & $-0.00004^{* * *}$ \\
NR4=(Prod)/PI & $-0.0374^{* * *}$ & $-0.06732^{* * *}$ \\
NR5=(Prod)/Pop & $-0.0064^{* *}$ & $-0.0567^{* * *}$ \\
NR6=(Prod)/Area & -0.0003 & $-0.0019^{* * *}$ \\
NR7=(Cumul.Prod)/Pop & $-0.0001^{* *}$ & $-0.0013^{* * *}$ \\
NR8=(Cumul.Prod)/Area & -0.0000 & $-0.00004^{* * *}$ \\
\hline \hline
\end{tabular}

* Significant at $10 \% ; * *$ significant at $5 \%$; *** significant at $1 \%$

\subsection{Conclusions and Policy Implications}

The primary merit of this analysis is that regions within the United States do not differ in dimensions such as language, institutional quality, and cultural attributes that are extremely difficult to control for in growth regressions, and therefore provide more precise estimates of the effect of resource abundance on growth. I choose a sample of counties based on exogenous criteria, as opposed to using the set of counties defined by the Appalachian Regional Commission, which present endogeneity concerns for the purposes of studying income growth. By comparing counties with varying sized coal industries, I look for evidence of a resource curse in the Appalachian region using 40 years of economic performance. I account for the possible endogeneity of the measure of resource abundance by using instrumental variable techniques. I find evidence that resource abundance does in fact act as a curse on growth in the sample of 
Appalachian counties. This paper has contributed to the strand of resource curse literature that shows that the resource curse is not restricted to developing nations.

Although the results of this study are derived from a specific regional context, they may be generalized with caution, and thus provide some guidance for policy. The broad implication of the results is that there is no empirical support for subsidizing resource extraction on basis of promoting economic growth. In addition, policy makers should consider the indirect costs of resource extraction that often arise because of boom and bust cycles in resource markets over the long run. Although a boom clearly provides tangible benefits in the short run, a bust in the market can have even larger negative effects over the long run. A common policy recommendation is the creation of a permanent trust fund, financed by severance taxes, that could be used to promote economic development by investing productively, thus compensating future generations for the loss of the resource. This approach is used by Norway and advocated by the International Monetary Fund when advising low-income countries. 


\section{Chapter 3}

\section{An Empirical Investigation of the Resource Curse Channels in Appalachia}

\subsection{Introduction}

Given evidence that growth is systematically lower for counties in the Appalachian region where coal dominates the local economy, I next investigate which channels are responsible for this effect. However, data on the county level is simply not available to fully assess each potential channel. For example, measures of rent seeking, corruption, and institutional quality on the county level are almost non-existent. Therefore, I limit this investigation to exploring several questions inspired by the resource curse literature for which data are available.

First, I explore the educational attainment channel and find evidence that educational attainment, as measured by either high school completion or college degree attainment, plays a significant role in this negative effect of coal abundance on income growth. A one standard deviation increase in coal abundance reduces average annual income growth through a reduction in high school completion by approximately 0.12 percentage points, while the college degree attainment measure implies a smaller reduction in average annual income growth of approximately 0.03 percentage points. Second, I study educational spending on the county level and find no evidence of any effects of coal resources. Third, I investigate the idea of Ross (2001) and Collier (2010) that resource abundance areas tend to under-tax the local population. I find that resource abundance is positively correlated with taxation, although the effect is not economically significant.

The remainder of the chapter is organized as follows. Section 3.2 studies the educational attainment channel. Section 3.3 investigates the effects of coal resources on county level educational spending. Section 3.4 investigates the effects of coal resources on county level taxation decisions, as measured by total county tax revenue per capita, and county property tax revenue per capita. Section 3.5 concludes and summarizes the results.

\subsection{Educational Attainment Channel}

I first study the educational attainment channel by examining how high school and college degree attainment are affected by coal abundance in Appalachia, and how educational attainment affects income growth. There is at least one theoretical reason why resource abundance may decrease the amount of education obtained by a local population. Many jobs in natural resource sectors do not require a high level of education. Thus as the natural resource sector expands 
relative to other sectors, wages of uneducated workers rise, and as a result the wage gap between educated and uneducated workers decreases, decreasing the expected long run benefits of education. At the same time, as wages of uneducated workers rise, the opportunity cost of obtaining an additional year of schooling rises as well, due to higher foregone earnings in the resource sector. Human capital theory predicts that an increase in the wages of uneducated workers relative to educated workers will reduce the incentive to invest in additional schooling, particularly if workers perceive the increase to be permanent (Mincer, 1958; Becker, 1964).

Black et al. (2005a) provide empirical support for this theory in the context of Appalachian coal mining during the 1970s to mid 1980s, and argue that workers perceived changes in the coal market during this period to be permanent, because it was a relatively long-term shock. They estimate that a $10 \%$ increase in earnings of low skilled workers during this boom period consequently decreased high school enrollment by about 5-7\%. The analysis here extends that of Black et al. (2005a) in several important ways. First, I examine the long run effects of boom and bust cycles in the coal market on educational attainment, versus examining the effects of one specific shock. Second, I explore whether or not the reduction in the fraction of individuals completing high school has any discernible effect on economic growth. Lastly, I examine the same effects related to college degree attainment in addition.

If these changes in the relative wage between educated and uneducated workers remain constant over time, then the benefits to uneducated workers are never reversed. However, given the commonly observed long run volatility of prices in natural resource markets, it is possible that downturns in the market for the resource eventually depress the wages of uneducated workers relative to educated workers once again. Black et al. (2005a) also provides evidence of this situation occurring during the mid 1980s decline of the coal market in Appalachia. Downturns in the market may arise from a negative supply shock, such as depletion, a positive supply shock, such as new discoveries in other regions, or changes in the price of related goods, such as oil. After a decline in the market for a natural resource, the population may be left with a lower level of human capital than they would have otherwise, without the resource.

Both theory and evidence suggest that human capital is an important determinant for economic growth. The theoretical macro growth literature describes three mechanisms by which education can positively influence economic growth. The first mechanism is increased labor productivity which results in higher equilibrium output. This is exemplified in neoclassical growth models. The second mechanism is the increased ability to create new technologies, (as in endogenous growth theories), and the third is the increased ability to implement new technologies 
and transmit knowledge. A wide empirical literature supports the importance of human capital to economic growth, especially human capital obtained through education, beginning with Barro (1991), and Mankiw, Romer and Weil (1992). Earlier empirical studies that estimated the effect of education on growth often used 'years of schooling' and enrollment rates as measures of human capital. Later studies such as Topel (1999), Barro and Lee (2000), and Krueger and Lindahl (2001) instead used measures of educational attainment to measure human capital, and also found evidence of positive effects on economic growth.

Education levels are high and rising in the United States, but the Appalachian region lags far behind the national average in terms of both high school completion and college degree attainment. Within the region educational attainment in coal mining counties lags slightly behind that of non-coal mining counties. Figure 3.1 shows that in the initial year of each decade, the mean share of residents without a high school diploma was higher in coal counties versus noncoal counties, with the widest margin occurring in 1990, after the 1980's decline in the coal market.

Figure 3.1: Mean Share of Population without a High School Diploma, by Year

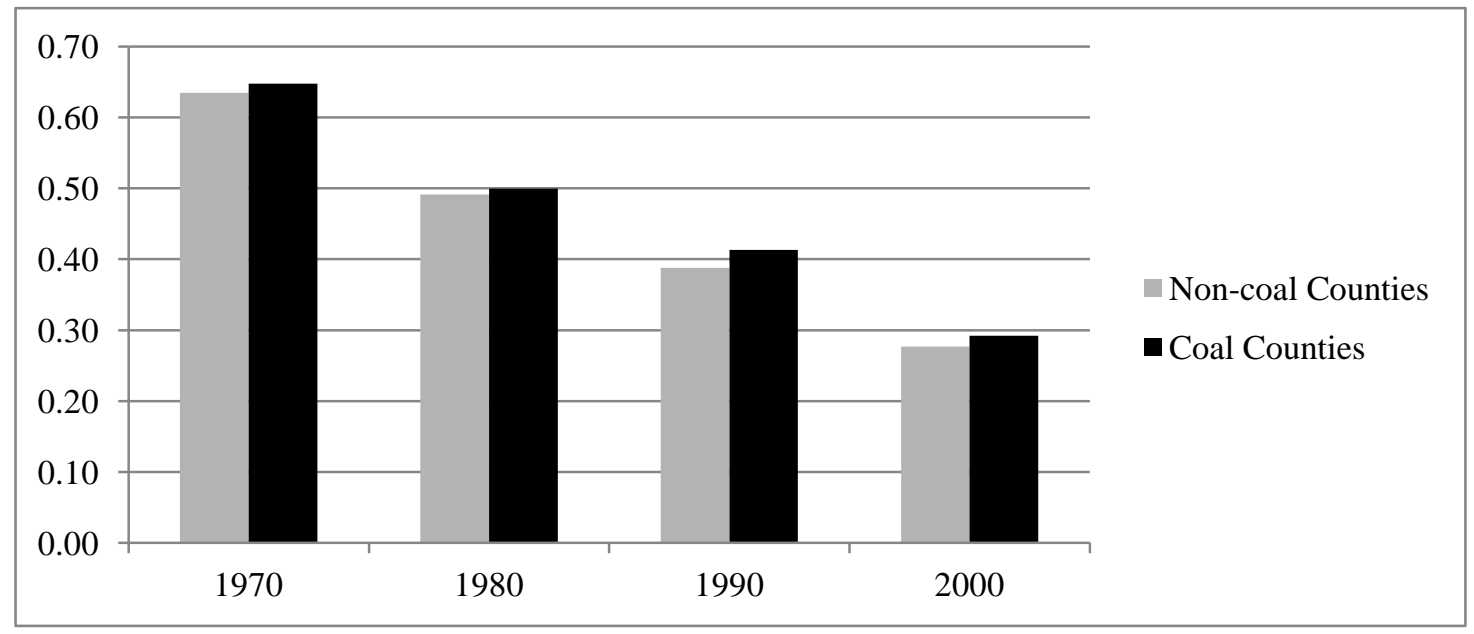

Figure 3.2 shows in the initial year of each decade, the mean proportion of residents with a college degree is higher for non-coal counties than for coal counties. In the year 2000, only about 11.5 percent of adults in coal counties and about 14 percent of adults in non-coal counties had a bachelor's degree or higher (compared to a national average of 24 percent). The most recent Census Bureau report currently available indicates that as of 2011, only 17.5 percent of adult West Virginians have earned a college degree or higher, compared to the national average of 30 percent, making West Virginia the state with the lowest proportion of college educated residents in the nation. 
Figure 3.2: Mean Share of Population with a Bachelor's Degree or Higher, by Year

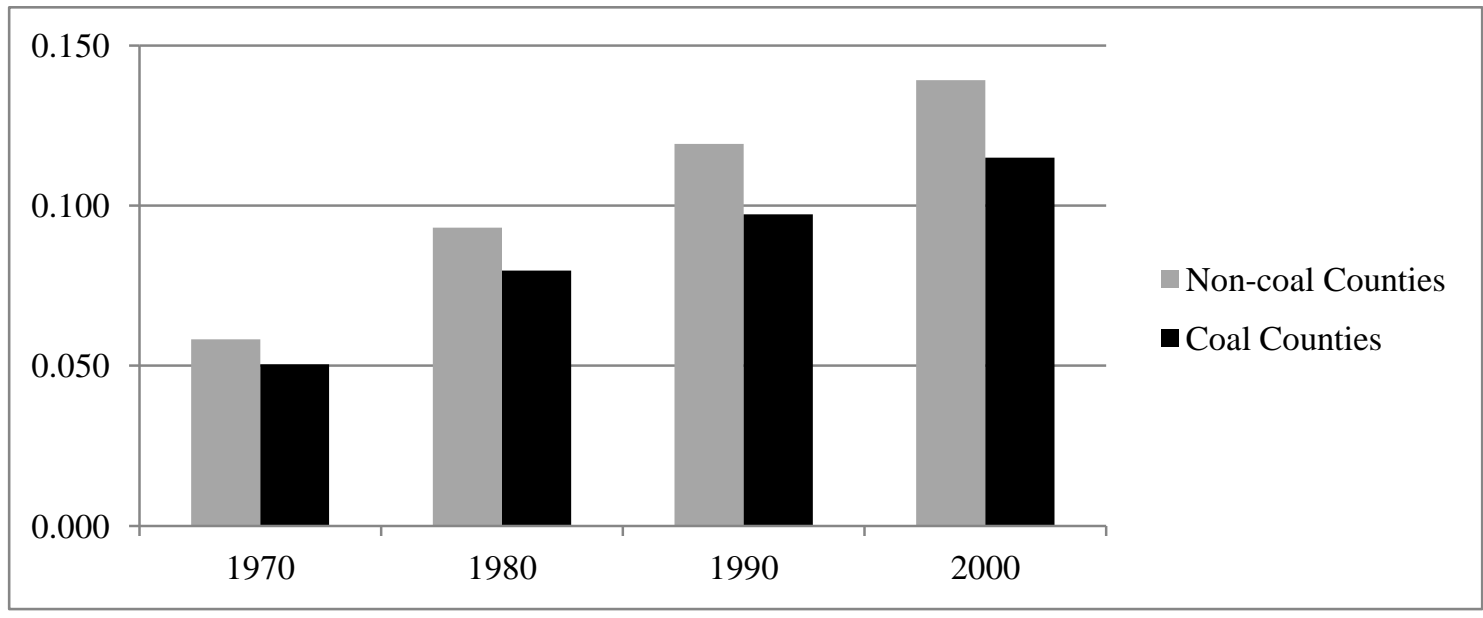

\subsubsection{Educational Attainment Model}

The resource curse literature has used several methods for exploring the channels through which the resource curse operates. Many cross-sectional resource curse studies such as Sachs and Warner $(1997,2001)$ simply add appropriate channel control variables to the right hand side of a growth regression. This method raises concerns of endogeneity since some channel control variables, for example education and intuitional quality, are likely not exogenous in a growth regression. Several papers in the literature such as Gylfason (2001), Papyrakis and Gerlagh (2004), and Papyrakis and Gerlagh (2007) use a simultaneous equation framework which allows for the channel variable to be treated endogenously. A simultaneous equation model (SEM) is appropriate because our prime explanatory variable, natural resource abundance, theoretically influences our dependent variable, economic growth, indirectly through the channel variable. I study the educational channel by formulating an SEM panel in which educational attainment affects the average growth rate of income in a county, while simultaneously being influenced by the presence of local natural resources, as shown below by equations (3.1) and (3.2):

$$
\begin{aligned}
& g_{i t}=\beta_{1} L n Y_{i t}+\beta_{2} N R_{i t}+\beta_{3} E d u_{i t}+\beta_{4} X_{i t}+\beta_{5} Y r_{t}+\mu_{s}+u_{i t} \\
& E d u_{i t}=\alpha_{1} L n Y_{i t}+\alpha_{2} N R_{i t}+\alpha_{3} E m p E d u_{i t}+\alpha_{4} \text { metro }_{i t}+\alpha_{5} \text { rural }_{t}+\alpha_{6} Y r_{t}+\lambda_{s}+e_{i t}
\end{aligned}
$$

This SEM model covers the same time-frame (1970-2010) with the same four time periods of growth (1970-80, 1980-90, 1990-2000, and 2000-2010). Equation (3.1) represents a structural growth equation, and is identical to the growth regression in equation (2b), but augmented with a term for educational attainment. Equation (3.2) represents a structural form equation for educational attainment. Educational attainment is measured by two different variables, both from the decennial Census. The first is the share of adults age 25 and over without a high school 
diploma (DropOut), and the second is the share of adults age 25 and over with a bachelor's degree or higher $(B a c h+)$, both measured in the initial year of the time period.

The indirect effect of resource abundance on economic growth via educational attainment is equal to the coefficient on the resource variable in the education equation $\left(\alpha_{2}\right)$ multiplied by the coefficient on education variable in the growth equation $\left(\beta_{3}\right)$. In the model, if the effect of DropOut on growth is negative $\left(\beta_{3}<0\right)$ and if the effect of coal resources on DropOut, is positive $\left(\alpha_{2}>0\right)$, then this would provide evidence that coal resources reduce growth by reducing the amount of people who graduate from high school. Using the Bach + measure instead, if the effect of Bach on growth is positive and significant $\left(\beta_{3}>0\right)$ and if the effect of coal resources on Bach is negative and significant $\left(\alpha_{2}<0\right)$, then coal resources reduce growth through reducing the amount of residents who obtain a college degree. Given theoretical explanations of the positive effect of education on growth, and the associated empirical evidence, I expect a positive and significant coefficient on the Bach+ variable and a negative and significant coefficient on the DropOut variable in equation (3.1).

Both measures of educational attainment are treated as endogenous variables in equation (3.1), given the likely reverse causal relationship between economic growth and education: regions with higher stocks of human capital typically grow faster, while increased income growth often leads to higher levels of investment in human capital (Bils \& Klenow, 2000; Goetz \& Hu, 1996). Resource abundance is once again treated as an endogenous variable in the growth regression, for the same reasons previously discussed. Therefore, instrumental variables for coal resources and for educational attainment are required to obtain consistent estimates for equation (3.1). The instruments for resource abundance in equation (3.1) are the same as for the first model: Coalo (a dummy equal to one if the county every produced coal commercially, as of the initial year of each period) and SlavePct1860 (the percentage of the population enslaved in 1860).

To select instruments for educational attainment, I draw on past literature that investigates the causal link between education and earnings. Several studies including Card (1993), Uusitalo \& Conneelly (1998), and Kane \& Rouse (1995) use geographic differences in the accessibility of college to isolate exogenous variation in educational decisions relative to earnings, while Maluccio (1998) uses distance to nearest high school. Currie \& Moretti (2003 QJE) use the availability of colleges in the woman's country as an instrument for maternal education in order to account for the endogeneity of educational attainment. Their study investigates the causal link between maternal education and birth outcomes. Card (2001) claims that the use of supply side variables (e.g. college proximity) to identify demand-side parameters is 
"a cornerstone of structural econometric methodology" (p.1157). The use of college proximity as an exogenous source of variation in educational choices in the context of average income growth relies on the assumption that college proximity affects income growth only through its effect on educational attainment. In other words, we must assume that counties with universities grow faster not because more residents are employed in the education sector, but because there is more human capital in those counties.

I use a proxy variable for college proximity as an exogenous instrument for educational attainment, EmplEdu, which is the fraction of the workforce employed in educational services, and gathered by the U.S. Census. This variable includes both private and public employment, as well as employment in K-12, community colleges, and four year colleges and universities, and is therefore representative of college proximity. A host of studies have shown that college proximity is strongly positively correlated with educational attainment choices, confirming that college proximity is a strong instrument (Card, 1993; Uusitalo \& Conneelly, 1997; Kane \& Rouse, 1995; Cameron and Heckman, 2001; Currie and Moretti, 2003). Card (1993) finds that college proximity has a strong effect on completed education even after controlling for parental education, region, and IQ. Proximity to school reduces the costs of schooling, and thereby positively affects an individual's decision to obtain additional schooling, all else equal.

To select variables for the model of educational attainment in equation (3.2), I draw on past literature that investigates the determinants of educational attainment, most of which are based on individual level survey data. For example, Cameron and Heckman (1993) found that factors such as gender, sibling numbers, parents' education, and family income influence the probability of entering college. At the aggregated level of counties, such variables are not feasible for inclusion in the model. Other studies have found that unemployment rates, average wage rates, and city size influence college degree attainment (Cohn and Hughes, 1994). The influence of urban areas will be accounted for by the Rural and Metro dummies, which are included in the vector of exogenous variables $X_{i t}$ in equation (3.1), and thus serve as included instruments. Initial income level $(\operatorname{Ln} Y)$ is also a determinant of college attendance (Cameron and Heckman (1993) that is included in equation (3.1) and thus serves as an included instrument in the SEM model. The EmplEdu variable is included to account for college proximity, as discussed above, and serves as an excluded instrument in the system.

The variable of prime interest in equation (3.2) is the coal natural resource variable, $N R$. It is set to the initial year of the 10 year period. A positive and significant coefficient on this variable provides evidence that coal resources decrease educational attainment. I have outlined 
the theoretical reason why one may expect this outcome, especially given the low educational requirements for coal miners in recent history and the existence of market booms which alter the relative wage of uneducated workers.

The state fixed effect term controls for any state specific factors affecting educational attainment that are constant over time. State fixed effects were chosen over county fixed effects since many policies, laws, and institutions related to education occur at the state level. The time fixed effect term controls for any long term trends in educational attainment that are common to all counties. Descriptions of all variable are shown in Appendix 1, and descriptive statistics for all variables are shown in Appendix 2.

First, equation (3.1) is estimated with OLS, ignoring the endogeneity of resource abundance and educational attainment. Next, I estimate equation (3.1) with 2SLS with CoalO and SlavePct 1860 serving as excluded instruments for resource abundance, and EmplEdu serving as an excluded instrument for educational attainment, and I estimate equation (3.2) with OLS. This estimation assumes that the $N R$ variable in equation (3.2) is exogenous, which is a reasonable assumption. In addition, I estimate both equations (3.1) and (3.2) with 3SLS. The 3SLS method uses generalized least squares (GLS) to account for the likely correlation of disturbances across equations. The 3SLS method also allows me to relax the assumption that $N R$ is exogenous in equation (3.2), since it is treated as an endogenous variable in the system estimation. All estimations use robust standard errors given that testing indicates the presence of heteroskedasticity.

\subsubsection{Education Attainment Model Results}

The results for equation (3.1) are shown in Table 3.1, and the results for equation (3.2) are shown in Table 3.2. The left hand panel in each table shows the results using the DropOut measure of educational attainment, and the right side shows the results using the Bach+ measure. The combined results in tables 3.1 and 3.2 provide support for the existence of an educational attainment channel through which coal resources hinder long-run growth in the sample of 409 Appalachian counties. The estimates for equation (3.1) show that educational attainment significantly and positively affect growth, while the estimates for equation (3.2) show that resource abundance significantly and negatively affects educational attainment.

Table 3.1 shows that the estimated coefficient for both measures of educational attainment in equation (3.1) are of the expected sign and are highly significant. The share of residents without a high school diploma is associated with lower income growth, with a 2SLS 
coefficient estimate of -0.0620 , implying that a one unit increase in the share of the population that drops out of high school lowers growth by about .06 percentage points annually. The share of residents with a college degree exerts a positive effect on income growth, with a 2SLS coefficient estimate of 0.0455 , implying positive influence on growth of approximately .04 percentage points annually with a unit increase in this measure.

If reduced educational attainment is a channel through which resources lower growth, adding a control for education to the growth regression, as in equation (3.1), implies that the negative coefficient on resource abundance should fall. Table 3.1 shows that the coefficient on coal abundance falls, but remains negative and significant in each specification, suggesting that although educational attainment is important, other channels in are important as well. The addition of either measure of educational attainment to the growth regression produces a drop in the coefficient for the coal abundance term, but the drop is much larger for the DropOut measure $(11 \%)$ than for the Bach+ measure (3\%), using 2SLS coefficients.

The estimates for equation (3.2) indicate that resource abundance significantly and negatively affects educational attainment. When human capital accumulation is measured by Bach+, the estimated 2SLS coefficient implies that the share of residents that obtain a college degree is reduced by approximately 1.6 percent over a forty year period. When human capital accumulation is measured by DropOut, the estimated 2SLS coefficient implies that the share of residents that don't complete high school is increased by about 4 percent. The 3SLS estimate of the effect of resource abundance is nearly identical for the DropOut measure, but is larger when using the Bach+ measure; signifying a reduction in the share of residents that obtain a college degree by approximately 2.8 percent. All of the estimated coefficients for the coal abundance term are significant at the one percent level. 
Table 3.1: Estimates of the effect of Coal Abundance and Educational Attainment on Economic Growth (Equation 3.1) Dependent Variable: Annualized Growth Rates of Per Capita Personal Income 1970-2010

Sample Size: $\mathrm{T}=4$ (1970-20010), N=409 Counties, total obs. $=1636$

\begin{tabular}{|c|c|c|c|c|c|c|}
\hline & \multicolumn{3}{|c|}{ Equation 3.1 with DropOut } & \multicolumn{3}{|c|}{ Equation 3.1with Bach+ } \\
\hline & (1) & $(2)$ & (3) & (1) & (2) & $(3)$ \\
\hline & OLS FE & $2 \mathrm{SLS}$ & 3SLS & OLS FE & $2 \mathrm{SLS}$ & 3SLS \\
\hline LnY(it) & $\begin{array}{c}-0.0249 * * * \\
(0.0030)\end{array}$ & $\begin{array}{c}-0.0332 * * * \\
(0.0045)\end{array}$ & $\begin{array}{c}-0.0279 * * * \\
(0.0035)\end{array}$ & $\begin{array}{c}-0.0232 * * * \\
(0.0016)\end{array}$ & $\begin{array}{c}-0.0231 * * * \\
(0.0023)\end{array}$ & $\begin{array}{c}-0.0217 * * * \\
(0.0018)\end{array}$ \\
\hline Metro County & $\begin{array}{c}0.0042 * * * \\
(0.0006)\end{array}$ & $\begin{array}{c}0.0033 * * * \\
(0.0007)\end{array}$ & $\begin{array}{c}0.0036 * * * \\
(0.0008)\end{array}$ & $\begin{array}{c}0.0040 * * * \\
(0.0006)\end{array}$ & $\begin{array}{c}0.0036 * * * \\
(0.0007)\end{array}$ & $\begin{array}{c}0.0037 * * * \\
(0.0007)\end{array}$ \\
\hline Rural County & $\begin{array}{r}-0.0001 \\
(0.0006)\end{array}$ & $\begin{array}{l}0.0005 \\
(0.0007)\end{array}$ & $\begin{array}{l}0.0002 \\
(0.0007)\end{array}$ & $\begin{array}{r}-0.0004 \\
(0.0006)\end{array}$ & $\begin{array}{r}-0.0002 \\
(0.0007)\end{array}$ & $\begin{array}{c}-0.0002 \\
(.0007)\end{array}$ \\
\hline Year 1970 & $\begin{array}{c}0.0156 * * * \\
(0.0051)\end{array}$ & $\begin{array}{c}0.0228 * * * \\
(0.0043)\end{array}$ & $\begin{array}{c}0.0172 * * * \\
(0.0034)\end{array}$ & $\begin{array}{c}0.0097 * * * \\
(0.0026)\end{array}$ & $\begin{array}{c}0.0088 * * * \\
(0.0011)\end{array}$ & $\begin{array}{c}0.0083 * * * \\
(0.001)\end{array}$ \\
\hline Year 1980 & $\begin{array}{c}0.0146 * * * \\
(0.0032)\end{array}$ & $\begin{array}{c}0.0195 * * * \\
(0.0025)\end{array}$ & $\begin{array}{c}0.0165 * * * \\
(0.0021)\end{array}$ & $\begin{array}{c}0.0110 * * * \\
(0.0024)\end{array}$ & $\begin{array}{c}0.0116 * * * \\
(0.0009)\end{array}$ & $\begin{array}{c}0.0112 * * * \\
(0.0009)\end{array}$ \\
\hline Year 1990 & $\begin{array}{c}0.0159 * * * \\
(0.0031)\end{array}$ & $\begin{array}{c}0.0187 * * * \\
(0.0015)\end{array}$ & $\begin{array}{c}0.0170 * * * \\
(0.0013)\end{array}$ & $\begin{array}{c}0.0137 * * * \\
(0.0025)\end{array}$ & $\begin{array}{c}0.0141 * * * \\
(0.0007)\end{array}$ & $\begin{array}{c}0.0140 * * * \\
(0.0008)\end{array}$ \\
\hline doilprice*NRdum & $\begin{array}{c}0.0063 * * * \\
(0.0014)\end{array}$ & $\begin{array}{c}0.0062 * * * \\
(0.0006)\end{array}$ & $\begin{array}{c}0.0064 * * * \\
(0.0005)\end{array}$ & $\begin{array}{c}0.0062 * * * \\
(0.0014)\end{array}$ & $\begin{array}{c}0.0063 * * * \\
(0.0006)\end{array}$ & $\begin{array}{c}0.0062 * * * \\
(0.0005)\end{array}$ \\
\hline NR & $\begin{array}{c}-0.0024 * * \\
(0.0010)\end{array}$ & $\begin{array}{c}-0.0142 * * * \\
(0.0026)\end{array}$ & $\begin{array}{c}-0.0148 * * * \\
(0.0026)\end{array}$ & $\begin{array}{c}-0.0031 * * * \\
(0.0007)\end{array}$ & $\begin{array}{c}-0.0155 * * * \\
(0.0026)\end{array}$ & $\begin{array}{c}-0.0156 * * * \\
(0.0026)\end{array}$ \\
\hline DropOut & $\begin{array}{c}-0.0313 * * \\
(0.0128)\end{array}$ & $\begin{array}{c}-0.0620 * * * \\
(0.0166)\end{array}$ & $\begin{array}{c}-0.0395 * * * \\
(0.0133)\end{array}$ & & & \\
\hline Bach+ & & & & $\begin{array}{c}0.0581 * * * \\
(0.0061)\end{array}$ & $\begin{array}{c}0.0455 * * * \\
(0.012)\end{array}$ & $\begin{array}{c}0.0296 * * * \\
(0.0095)\end{array}$ \\
\hline Constant & $\begin{array}{c}0.2465 * * * \\
(0.0322)\end{array}$ & & $\begin{array}{c}0.2797 * * * \\
(0.0378)\end{array}$ & $\begin{array}{c}0.2137 * * * \\
(0.0156)\end{array}$ & & $\begin{array}{c}0.2029 * * * \\
(0.0167)\end{array}$ \\
\hline $\begin{array}{l}\text { Observations } \\
\text { R-squared }\end{array}$ & $\begin{array}{c}1636 \\
0.41 \\
\end{array}$ & 1636 & 1636 & $\begin{array}{c}1636 \\
0.43 \\
\end{array}$ & 1636 & 1636 \\
\hline $\begin{array}{l}\text { Hansen } \mathrm{J} \text { test } \\
\text { Ho: IV's are exogenous. }\end{array}$ & & $\begin{array}{c}0.614 \\
(0.4332)\end{array}$ & & & $\begin{array}{c}0.632 \\
(0.4267)\end{array}$ & \\
\hline
\end{tabular}

Robust standard errors in parenthesis.

* Significant at $10 \%$; ** significant at $5 \%$; *** significant at $1 \%$ 
Table 3.2: Estimates of the effect of Coal Abundance on Educational Attainment (Equation 3.2) Dependent Variable: Stock of Educational Attainment during Initial Year of Period Sample Size: $\mathrm{T}=4$ (1970-20010), N=409 Counties, total obs. $=1636$

\begin{tabular}{|c|c|c|c|c|}
\hline & \multicolumn{2}{|c|}{ Equation 3.2 with DropOut } & \multicolumn{2}{|c|}{ Equation 3.2 with Bach+ } \\
\hline & (2) & (3) & (2) & (3) \\
\hline & OLS FE & 3SLS & OLS FE & 3SLS \\
\hline $\operatorname{LnY}(i t-\tau)$ & $\begin{array}{c}-0.2515 * * * \\
(0.0142)\end{array}$ & $\begin{array}{c}-0.2513 * * * \\
(0.0060)\end{array}$ & $\begin{array}{c}0.1233 * * * \\
(0.0144)\end{array}$ & $\begin{array}{c}0.1223 * * * \\
(0.0035)\end{array}$ \\
\hline Metro County & $\begin{array}{c}-0.0103 * \\
(0.0049)\end{array}$ & $\begin{array}{c}-0.0102 * * * \\
(0.0030)\end{array}$ & $\begin{array}{c}0.0085 * * * \\
(0.0027)\end{array}$ & $\begin{array}{c}0.0080 * * * \\
(0.0017)\end{array}$ \\
\hline Rural County & $\begin{array}{c}0.0087 * \\
(0.0042)\end{array}$ & $\begin{array}{c}0.0087 * * * \\
(0.0029)\end{array}$ & $\begin{array}{l}0.0024 \\
(0.0023)\end{array}$ & $\begin{array}{l}0.0026 \\
(0.0016)\end{array}$ \\
\hline Year 1970 & $\begin{array}{c}0.2364 * * * \\
(0.0081)\end{array}$ & $\begin{array}{c}0.2364 * * * \\
(0.0039)\end{array}$ & $\begin{array}{c}-0.0133 * * \\
(0.0050)\end{array}$ & $\begin{array}{c}-0.0137 * * * \\
(0.0023)\end{array}$ \\
\hline Year 1980 & $\begin{array}{c}0.1331 * * * \\
(0.0064)\end{array}$ & $\begin{array}{c}0.1330 * * * \\
(0.0034)\end{array}$ & $\begin{array}{c}-0.0060 * \\
(0.0033)\end{array}$ & $\begin{array}{c}-0.0053 * * * \\
(0.0020)\end{array}$ \\
\hline Year 1990 & $\begin{array}{c}0.0713 * * * \\
(0.0038)\end{array}$ & $\begin{array}{c}0.0712 * * * \\
(0.0031)\end{array}$ & $\begin{array}{c}0.0050 * * * \\
(0.0014)\end{array}$ & $\begin{array}{c}0.0054 * * * \\
(0.0018)\end{array}$ \\
\hline N.R. & $\begin{array}{c}0.0402 * * * \\
(0.0104)\end{array}$ & $\begin{array}{c}0.0421 * * * \\
(0.0110)\end{array}$ & $\begin{array}{c}-0.0161 * * * \\
(0.0024)\end{array}$ & $\begin{array}{c}-0.0279 * * * \\
(0.0063)\end{array}$ \\
\hline EmpEdu & $\begin{array}{c}-0.5837 * * * \\
(0.0576)\end{array}$ & $\begin{array}{c}-0.5839 * * * \\
(0.0334)\end{array}$ & $\begin{array}{c}0.7835 * * * \\
(0.0383)\end{array}$ & $\begin{array}{c}0.7851 * * * \\
(0.0190)\end{array}$ \\
\hline Constant & $\begin{array}{c}2.7733 * * * \\
(0.1396)\end{array}$ & $\begin{array}{c}2.8021 * * * \\
(0.0592)\end{array}$ & $\begin{array}{c}-1.1375^{* * *} * \\
(0.1402)\end{array}$ & $\begin{array}{c}-1.1262 * * * * \\
(0.0342)\end{array}$ \\
\hline Observations & 1636 & 1636 & 1636 & 1636 \\
\hline R-squared & 0.92 & & 0.77 & \\
\hline
\end{tabular}

Robust standard errors in parenthesis.

* Significant at $10 \%$; ** significant at 5\%; *** significant at $1 \%$

Table 3.3 summarizes the resulting 2SLS and 3SLS estimates of the indirect effect of resource abundance on growth via educational attainment. Using the DropOut measure of attainment, the 2SLS indirect effect of resource abundance via educational attainment is the product of the estimated coefficient on $E d u$ in the growth regression $\left(\beta_{3}=-0.0620\right)$ multiplied by the estimated coefficient on $N R$ in the education equation $\left(\alpha_{2}=0.0402\right)$, which equals -0.0025 . Using the Bach + measure of education, the estimated 2SLS coefficient on $E d u$ in the growth regression $\left(\beta_{3}=0.0455\right)$ multiplied by the estimated coefficient on $N R$ in the education equation $\left(\alpha_{2}=-0.0161\right)$, equals -0.0007 . These estimates imply that a one unit increase in coal abundance reduces average annual income growth through a reduction in high school completion by approximately 0.25 percentage points. When education is measured by college degree attainment, the estimates imply a reduction in average annual income growth of approximately 0.07 percentage points. In terms of standard deviations, the estimates imply that a one standard deviation 
increase in coal abundance reduces average annual income growth through a reduction in high school completion by approximately 0.125 percentage points, while the college degree attainment measure implies a reduction in average annual income growth of approximately 0.037 percentage points.

Table 3.3: Estimates of the Indirect Effect of Coal Abundance on Education Indirect effect on growth:

\begin{tabular}{ccccc}
\cline { 3 - 5 } \cline { 4 - 5 } DropOut & $\left(\boldsymbol{\beta}_{\mathbf{3}} * \boldsymbol{\alpha}_{\mathbf{2}}\right)$ & One Unit Increase in NR: & One Std. Dev Increase in NR: \\
\hline \hline & 2SLS & -0.0025 & -0.25 percentage points & -0.125 percentage points \\
Bach + & 3SLS & -0.0017 & -0.17 percentage points & -0.083 percentage points \\
\hline \hline
\end{tabular}

The 3SLS estimates yield similar sized estimates, especially for the Bach+ measure of attainment. For the Bach + measure of attainment, the estimated indirect effect based on the 3SLS estimation is that a one standard deviation increase in coal abundance reduces average annual income growth by 0.041 percentage points (versus 0.037 percentage points per the 2 SLS method). But for the DropOut measure of attainment, the estimated indirect effect based on the 3SLS estimation is about one third smaller in magnitude: a one standard deviation increase in coal abundance reduces average annual income growth through by 0.083 percentage points (versus 0.125 percentage points per the 2 SLS method). For the 3SLS estimations, the standard error of $\left(\beta_{3} * \alpha_{2}\right)$ for DropOut is 0.0007 and for Bach+ it is 0.0004 .

The results indicate that the overall indirect (and negative) effect of coal resources on growth through reduced educational attainment is larger when measured by DropOut than by Bach+. The estimated effect of each of these measures on growth is similar in magnitude, but the estimated effect of resource abundance on DropOut is much larger than the effect on Bach+, according to both the 2SLS and 3SLS results. This result is not surprising given that the coal industry typically did not require high school diplomas to work in coal mines during most of the study period. Since a (public) high school education is free unlike a college education, the opportunity costs of attending high school represent the main source of costs. Therefore, the change in opportunity cost for additional years of education impacts individuals in high school to a larger degree. Also, Black (2005a) notes that individuals were likely to perceive the boom in the coal market in the late 1970s as a relatively long term change. Therefore, the individual's expected discounted benefits of completing high school (or college) were lowered.

Tests confirm the joint endogeneity of the natural resource and educational attainment variables in equation (3.1), and thus the need for instruments. Table 3.3 shows the results of the Hansen $\mathrm{J}$ test of instrument exogeneity for the 2SLS estimations. The Hansen J statistic has a p-value of 0.4332 for the 
DropOut measure, and 0.4267 for the Bach + measure of attainment, each indicating a failure to reject the null hypothesis of instrument exogoeneity. Appendix 5 shows the 2SLS first stage results for both measures of educational attainment, including the Angrist-Pischke first stage F statistic and associated pvalue. The p-value of the Angrist-Pischke first stage F statistic is 0.0000 for both measures of educational attainment, indicating a rejection of the null hypothesis. In addition, for both measures educational attainment, the coefficients on the instrument EmplEdu are highly significant and have the expected sign.

In summary, the combined results from tables 3.3 and 3.4 provide evidence that coal producing counties have lower levels of human capital due to the abundance of coal, and those lower levels of human capital in turn harm per capita income growth over the long run. These results are consistent with Gylfason et al. (1999), Gylfason (2001), Black et al. (2005a), and Papyrakis and Gerlagh (2007), which all find a negative effect of resource abundance on schooling. Relatively high paying jobs in the resource sector increase the opportunity cost of schooling and decrease the expected discounted benefits of schooling, or the wage gap between uneducated and educated workers. The benefits of foregoing additional education may be short-lived, as the local resource could be depleted; boom and bust cycles may occur; and increased mechanization within the mining industry may all negatively impact employment and earning prospects over the longer term.

\subsection{The Educational Spending Channel}

Much of the resource curse literature in political science emphasizes 'weak governance' as key cause of the resource curse (Ross, 2001; Collier, 2010). Collier (2010) claims that the resource curse is confined to countries with weak governance. Boom and bust cycles and the depletion of natural resources can have important implications for governments' management of resource revenues. One often cited example of 'weak governance' is the failure of governments to invest in growth promoting activities, especially education. But like individuals, governments have less incentive to invest in education in the presence of a relatively high paying resource sector. Governments may be lured into a false sense of security during a resource boom, and fail to make wise decisions that promote future growth, including investment in education. Empirical evidence has shown that public expenditure on education relative to national income is generally lower in countries with an abundance of natural resources (Glyfason, 2001). The question is whether or not this impact occurs on the local level as well. Two unpublished dissertations have examined this question. Dunn (2008) used U.S. state level data and found that an increase in resource intensity is associated with a reduction in expenditure per pupil. In contrast, Harkness (2010) found that coal counties in Kentucky actually invest more in education than non-coal counties. 
Governments typically play a large role in human capital accumulation by allocating tax revenue for schooling. However, empirical evidence for the effects of public educational expenditures on economic growth is mixed. Cullison (1993), Zhang and Casagrande (1998), Barro and Sala-i-Martin (1999), and Blankenau et al. (2007) all find a positive relationship between government education spending and growth. Easterly and Rebelo (1993) find this relationship holds only for certain specifications. Levine and Renelt (1992) find that government education expenditures are not a robust correlate of with growth rates. Devarajan, Swaroop, and Zou (1996) even find negative correlations between the share education expenditures in government budget and economic growth in most of their estimates.

Education funding in the United States is primarily the responsibility of the state and local governments. Across the U.S., the average share of education funding from state governments is about $46 \%$ and the average share from local governments is about $37 \%$. $^{13}$ State and local laws pertaining to education funding vary widely. For example, in some states, including Maryland, Tennessee, and Virginia, the county government is the primary provider of public education. In other states such as West Virginia and Kentucky, a mandated percentage of local property taxes (90\% in West Virginia) are submitted to the state, which uses a formula process to redistribute funds for education to each county. For such states, the state is the primary provider of educational funding, but each county may also independently levy an additional property tax specifically for school funding which stays in the county.

Mean EduExpShare for coal and non-coal counties are shown in Table 3.5. Non-coal counties have substantially higher educational expenditure shares than coal counties for all years shown. However, the coal counties are disproportionately located in states where the state-level government is the primary provider of education, such as West Virginia and Kentucky, and these counties tend to devote less of their local budgets to education. Likewise, many non-coal counties are located in states such as Maryland, Tennessee, and Virginia where the county is the primary funder of education, and these states tend to devote larger percentage of local funds to education.

Table 3.4: Mean Education Expenditure Share, by Year

\begin{tabular}{lcccc} 
& 1970 & 1980 & 1990 & 2000 \\
\hline \hline Non-coal Counties & 0.27 & 0.26 & 0.25 & 0.23 \\
Coal Counties & 0.12 & 0.10 & 0.10 & 0.08 \\
\hline \hline
\end{tabular}

\subsubsection{Educational Spending Channel Model}

I specify the following equation to investigate the effect of coal abundance on county level educational spending:

\footnotetext{
13 Data from 2004-2005, from http://www2.ed.gov/about/overview/fed/10facts/index.html.
} 
EduExpShare $_{i t}=\alpha_{1}$ LnY $_{i t-1}+\alpha_{2}$ Rural $_{i t-1}+\alpha_{3}$ Metro $_{i t-1}+\alpha_{4}$ NR $_{i t-1}+\alpha_{5}$ Enroll $_{i t-1}+$ $\alpha_{6}$ Age65Up $_{i t-1}+\alpha_{7}$ PropTaxPC $_{i t}+Y_{t}+\mu_{s}+\varepsilon_{i t}$

The panel model covers the same time period, 1970-2010, with the same four time windows. The dependent variable, EduExpShare is defined as the county's educational expenditures divided by county's total expenditures, or the share of county expenditures on education. Adjusting the educational expenditures measure based on total county expenditures accounts for different sized counties. Even in states where the state-level government is the primary funder of education, counties still have discretion over their own budgets.

The control variables were selected based on past literature investigating the determinants of educational spending. Fernandez and Rogerson (2001) find that the two most important determinants of spending across states are personal income and number of students. Thus lagged log personal income $\left(\operatorname{Ln} Y_{i t-1}\right)$ and the share of elementary and high school students in the population $\left(\right.$ Enroll $\left._{i t-1}\right)$ are included as controls. Porterba (1998) found that an increase in the fraction of elderly residents significantly reduces educational spending. The variable $A g e 65 U p_{i t-1}$ represents the fraction of the population age 65 and over. Also included are the rural and metro dummies and current period property

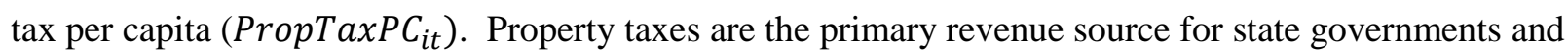
thus for educational funding. Lastly, the model includes state and time fixed effects. The model employs state fixed effects instead of county-level fixed effects since state-level laws provide the legal framework for educational spending.

The variable of interest in equation (3) is the lagged resource abundance variable. The $N R$ variable is lagged one period since the dependent variable is set to the initial year of the time period. The effects of $N R$ likely occur with at least a small lag, versus an instantaneous change. In addition, the lagged period resource term can be considered as exogenous since it is not likely impacted by current period county educational expenditure share, or correlated with confounding factors that affect the current ratio of educational expenditures to total expenditure. The model will therefore be estimated with OLS. I test the null hypothesis that resource abundance has no significant effect on local educational expenditures $\left(H_{o}: \alpha_{2} \geq 0\right)$ against the alternative that resource abundance negatively impacts educational expenditure share $\left(H_{A}: \alpha_{2}<0\right)$. Rejection of the null hypothesis is evidence that resource abundance tends to curb educational spending.

\subsubsection{Educational Spending Model Results}

Equation (3.3) investigates the question of whether or not resource abundance has an effect on the educational expenditure decisions of local governments. It was estimated using OLS, with robust standard errors, and state fixed effects. The results shown in Table 3.6 indicate that coal abundance is not 
significantly correlated with the share of expenditures devoted to education for local county governments. This result does not preclude the possibility that state-level government decisions regarding educational expenditures may be influenced by resource abundance, as found in Dunn (2008). The results do not change if the sample is limited to only those states where the county is the primary funder of education.

Table 3.5: Estimates of the effect of Resource Abundance on County Educational Expenditure Share

Dependent Variable: Share of County's Total Expenditures on Education Sample Size: $\mathrm{T}=4$ (1970-20010), N=409 Counties, total obs. $=1636$

\begin{tabular}{ll}
\hline \hline & OLS FE \\
\hline Lag LnY(it) & -0.0306 \\
& $(0.0233)$ \\
Lag Metro County & 0.0085 \\
& $(0.0054)$ \\
Lag Rural County & 0.0005 \\
& $(0.0058)$ \\
Year 1980 & 0.0026 \\
& $(0.0144)$ \\
Year 1990 & 0.0029 \\
& $(0.0133)$ \\
Lag NR & -0.0008 \\
& $(0.0040)$ \\
Lag Enroll & -0.2372 \\
Lag Age65+ & $(0.1580)$ \\
& -0.1828 \\
Property Tax Per Capita & $(0.1215)$ \\
& $-0.0749^{* *}$ \\
Constant & $(0.0283)$ \\
& $0.5576^{* *}$ \\
\hline Observations & $(0.2558)$ \\
R-squared & 1226 \\
\hline \hline Robust & 0.03 \\
\hline
\end{tabular}

Robust standard errors in parenthesis.

* Significant at $10 \%$; * significant at $5 \%$; *** significant at $1 \%$

In contrast to findings in Porterba (1998), the proportion of elderly residents has no significant effect on a county's share of expenditures devoted to education. The fraction of students enrolled in elementary and high school lagged initial log income was also not correlated with educational expenditure share of local governments, contrary to the finding in Fernandez and Rogerson (2001) using state-level data. The rural and metro variables were not significant either, nor were the year fixed effects. Only the constant term and the property tax per capita term were significant, however, the sign on PropTaxPC is negative. 
This may be due to the redistribution of education funds from richer counties (usually more urban) to poorer counties (usually more rural) in states that use a formula redistribution process.

\subsection{Under-Taxation Due to Resource Abundance}

Another claim in the resource curse literature that is associated with the 'weak governance' channel is that tax revenue from natural resources free governments from taxing the public, leading to less demand for accountability from the public, thereby decreasing democracy and worsening political outcomes. (Ross 2001). The claim relies on the assumption that greater taxation by a sovereign leads to greater demand for representation by the people. The reduced scrutiny may also result in increased corruption by politicians. Collier (2010) explains that resource revenue is a source of income that does not provoke as much scrutiny as taxing people's incomes. Taxpayer scrutiny tends to inhibit politicians' ability to expropriate natural resource revenue. Corrupt politicians often use resource revenue to offset income taxation, so that in the end, total revenue is no higher, but politicians are less accountable for its expenditure. One possible result is that investment on public goods, particularly education and health care, is reduced, potentially harming growth.

A few studies have empirically investigated this claim. In an unpublished dissertation, Harkness (2010) examines the first part of the claim; that resource abundance leads to lower taxation, using property tax rates across Kentucky counties between 2002 and 2006. Harkenss (2010) finds the claim to be false; resource rich counties in Kentucky actually tax their populations at higher rates than resourcepoor counties. Goldberg, Wibbels, and Mvukiyehe (2008) uses U.S. state level data and finds evidence that natural resource dependence (as measured by the value of annual oil and coal production as a share of state income) is negatively correlated with a measure of "taxation effort" by the state. Using international data, Ross (2001) examines the second part of the claim that lower taxes lead to less democracy and finds that governments do in fact use low tax rates to reduce pressures for democracy.

\subsubsection{Under-Taxation Model}

I construct a simple panel model of tax revenue per capita (TaxPC), covering the same four time periods in order to investigate the relationship between local government taxation decisions and resource dependence:

$\operatorname{TaxPC}_{i t}=\alpha_{1} \operatorname{LnY}_{i t-1}+\alpha_{2}$ Metro $_{i t-1}+\alpha_{3}$ Rural $_{i t-1}+\alpha_{4} N R_{i t}+\alpha_{5} N R_{i t-1}+\alpha_{6} Y_{t}+\mu_{s}+\varepsilon_{i t}$

I use two measures of taxation; the first measure is property tax revenue per capita of county $i$ (PropTaxPC), and the second measure is total tax revenue per capita of county $i$ (TotTaxPC). Property taxes are typically the largest source of tax revenue for local governments. I estimate the model with each measure of taxation. 
Both variables were obtained from the Census of County Governments, which is collected every five years on years ending in seven and two. I used the 1967 data for the period beginning in 1970, 1977 data for the period beginning in 1980, 1987 data for the period beginning in 1990, and 1997 data for the period beginning in 2000. Property taxes are levied on real and personal property held within the county by individuals and businesses. Property tax revenue is the largest component of total tax revenue for most counties. Total tax revenue for a county also includes non-property tax revenue, which is predominantly composed of sales tax revenue, but also includes several other minor categories such as motor vehicle tax fees and business license fees. West Virginia is the only state in the data with a "Business and Operation" tax, so revenue from this tax is included in total tax revenue for counties in that state. Any severance taxes imposed by states are not included in this category.

The ideal measure of taxation should capture the relative level of 'taxation effort' by a county to levy taxation on the general public. If the theory of Ross (2001) and Collier (2010) also applies to the coal producing counties of Appalachia, then the model would result in a negative coefficient for the resources abundance variable. However, the measures of 'taxation effort' employed here, property tax revenue per capita and total tax revenue per capita, are flawed. In Appalachia, some coal companies privately own the lands containing mines, and therefore pay property taxes on those lands. Furthermore, in some states (e.g. West Virginia and Kentucky), ownership of mineral rights is separated from land ownership, and subject to property taxation as well. These components of property taxation will produce upward bias in the coefficient estimate for resource abundance for both measures of taxation, since each includes some amount of property taxes paid by coal producers. In future studies, a more appropriate measure would be a county level equivalent measure to the one used by Goldberg et al. (2008), which uses a measure of "taxation effort." Taxation effort measures the extent to which a government utilizes its taxing capacity. Goldberg et al. (2008) calculated taxation effort by subtracting a measure of taxing capacity from actual taxation, based on Berry and Fording (1997). Tax capacity is defined as the capability of a governmental entity to finance its public services.

The most commonly used state level measure of taxation effort is produced by the Advisory Commission on Intergovernmental Relations (ACIR). The ACIR provides no such measure for counties, but several authors have calculated individual county-level measures of taxation effort by using the ACIR methodology, for example Hy, Boland, Hopper, and Sims (1993) and Hoyt (2003). The ACIR defines tax capacity as the amount of revenue that the state would collect if it applied the national-average tax rate to its own tax base. They create a tax-capacity index by dividing a state's per capita tax capacity by the average value of per capita tax capacity across states. To create the tax effort variable, the ACIR calculates the ratio of a state's tax collections to its tax capacity. Finally, they calculate a tax-effort index 
by dividing each state's tax effort by the average value of effort across states and multiplying by 100 . Scores above 100 indicate above-average taxation efforts and scores below 100 indicate below-average efforts.

Both the current period resource abundance variable and its lagged value are included as variables of prime interest in the model. I test the null hypothesis that resource abundance has no positive current or lagged effects on local level taxation decisions $\left(H_{o}: \alpha_{4} \geq 0\right.$ and $\left.\alpha_{5} \geq 0\right)$ against the alternative that resource abundance negatively impacts tax revenue per capita $\left(H_{A}: \alpha_{4}<0\right.$ and $\left.\alpha_{5}<0\right)$. Rejection of the null hypothesis is evidence that resource abundance tends to decrease the amount of property or total taxes per capita collected by county governments. The resource abundance variable can be considered as exogenous since it is not likely impacted by county tax rates, or correlated with omitted factors that affect county level tax rates. The model will therefore be estimated with OLS.

Since the taxation variable are measured in the initial year of the period, I lag the majority of the control variables both to help mitigate endogeneity and to allow for the likely time lag in possible effects on county level taxation. The controls include lagged initial personal income, since this signifies a viable tax base. I include lagged dummies for urban and rural areas. Rural areas are more sparsely populated and land owners often own larger quantities of land, and therefore this variable may be positively correlated with property taxation. Lastly, I include state and time fixed effects for the same reasons previously discussed.

Tables 3.7and 3.8 show descriptive statistics for the two measures of local level taxation per capita. For both measures, for all years shown, taxes of coal counties are lower than those of non-coal counties, which appear to potentially support Ross and Collier's theory of under-taxation of resource rich regions related to national governments.

Table 3.6: Mean Property Taxes Per Capita, by Year (in Dollars)

\begin{tabular}{lcccc} 
& 1970 & 1980 & 1990 & 2000 \\
\hline \hline Non-coal Counties & 0.03 & 0.05 & 0.10 & 0.17 \\
Coal Counties & 0.02 & 0.03 & 0.06 & 0.11 \\
\hline \hline
\end{tabular}

Table 3.7: Mean Total County Taxes Per Capita, by Year (in Dollars)

\begin{tabular}{lcccc} 
& 1970 & 1980 & 1990 & 2000 \\
\hline \hline Non-coal Counties & 0.05 & 0.07 & 0.16 & 0.28 \\
Coal Counties & 0.03 & 0.04 & 0.09 & 0.15 \\
\hline \hline
\end{tabular}




\subsubsection{Under-Taxation Model Results}

Equation (4) investigates the question of whether resource abundance contributes to relatively lower taxation effort by local governments. It was estimated using OLS, with robust standard errors, and statelevel fixed effects. The results shown in Table 3.9 indicate that resource abundance has contrasting effects with respect to time on both property tax revenue per capita and total tax revenue per capita. Current period resource abundance has a positive and significant effect on both measures of tax revenue, while lagged period resource abundance has a negative and significant effect on both measures of tax revenue. The current period coefficients are significant at the $1 \%$ level, and the lagged period coefficients are significant at the 5\% level. Also for both measures, the magnitude of the contemporaneous positive effect of local resources outweighs the magnitude of the lagged negative effect of resources on taxation per capita. The estimated coefficients indicate that the net long-run effect of a unit increase in the resource abundance variable is associated with an increase in property taxes per capita of $\$ .0076$ and an increase in total taxes per capita of $\$ .0168$. The intent of the taxation measures is to capture the effects of resource abundance on local governments' efforts to tax the public in general. But as previously discussed, the coefficient estimates produced using these measures of taxation effort are almost certainly upward biased, since both measures include property tax revenue paid by coal producers. Future studies should utilize more sophisticated measure of taxation effort, such as those proposed by Goldberg et al (2008), or the county-level equivalent of the ACIR's state level measure.

Other control variables that were significant include lagged log income per capita, the lagged rural dummy, and the time fixed effects. Lagged log income per capita has a positive effect on both measures of tax revenue, which is no surprise, since it indicates that people have more taxable resources in general. The lagged rural dummy estimated coefficient indicates a positive effect of rurality on both measures of tax revenue, which is likely due to the measurement of tax revenue being on a per capita basis. Since rural areas are more sparsely populated, each citizen pays more on average. In addition, people tend to own larger tracts of land in rural areas, increasing the amount of property taxes paid per capita.

In summary, my preliminary results do not support extending to Appalachian county governments the result found in the international resource curse literature that governments under-tax the public in order to circumvent accountability and expropriate resource rents. Improved measures of taxation effort by county level governments are needed to address this question more thoroughly. Given the finding of Harkenss (2010) that Kentucky coal counties levy higher tax rates than non-coal counties, more detailed research based on improved measures of taxation effort by local governments is warranted in order to shed light on this potential effect of resource abundance. 
Table 3.8: Estimates of the effect of Resource Abundance on Tax Revenues Per Capita of County Government

Dependent Variable: County Tax Revenue Per Capita Sample Size: T=4 (1970-20010), N=409 Counties, total obs. = 1636

\begin{tabular}{lc|c}
\hline \hline & $\begin{array}{c}\text { Dependent Variable: } \\
\text { PropTaxPC }\end{array}$ & $\begin{array}{c}\text { Dependent Variable: } \\
\text { TotTaxPC }\end{array}$ \\
\hline \hline LnY(it-2 $\tau)$ & OLS FE & OLS FE \\
Lagged Metro & $(0.0736 * *$ & $0.1249 * * *$ \\
& -0.0045 & $(0.0394)$ \\
Lagged Rural & $(0.0061)$ & -0.0018 \\
& $0.0181 * *$ & $(0.0076)$ \\
Year 1980 & $(0.0078)$ & $0.0221 *$ \\
& $-0.0961 * * *$ & $(0.0114)$ \\
Year 1990 & $(0.0184)$ & $-0.1522 * * *$ \\
& $-0.0555^{*} * *$ & $(0.033)$ \\
NR & $(0.012)$ & $-0.0860 * * *$ \\
& $0.0314 * * *$ & $(0.0189)$ \\
Lagged NR & $(0.0079)$ & $0.0572 * * *$ \\
& $-0.0238^{* *}$ & $(0.0163)$ \\
Constant & $(0.0082)$ & $-0.0404 * *$ \\
& $-0.5564 *$ & $(0.0149)$ \\
Observations & $(0.2576)$ & $-0.9649 * *$ \\
R-squared & 1226 & $(0.366)$ \\
\hline Robus & 0.32 & 1226 \\
& 0.44 & 0.44 \\
\hline
\end{tabular}

Robust standard errors in parenthesis.

* Significant at $10 \%$; ** significant at $5 \%$; *** significant at $1 \%$

\subsection{Conclusion}

In this chapter I have investigated several of the causes for the under-performance by many resource rich counties in the Appalachian region. I examine the effect of coal abundance on educational attainment, local (county) level education expenditure decisions, and local level taxation decisions. I find evidence that the educational attainment channel accounts for a significant portion of the negative effect of resource abundance. I find no evidence that resource abundance affects the education expenditure allocation decisions of local county governments, nor do I find evidence that resource rich counties test to under tax their populations. In fact, coal abundance is positively correlated with taxation. 


\section{APPENDIX}

\section{Appendix 1: Variable Descriptions and Sources}

\begin{tabular}{|c|c|c|}
\hline Variable & Description & Source \\
\hline git & Average annual growth of real per capita person income & BEA \\
\hline $\operatorname{Ln} Y(i t)$ & Beginning of period real per capita personal income & BEA \\
\hline Metro County & $=1$ if Beale code $\leq 3$ (Metro area) & USDA \\
\hline Rural County & $\begin{array}{l}=1 \text { if Beale code } \geq 7 \text { (Very rural, or popuation }< \\
20,000, \text { not adjacent to an urban county) }\end{array}$ & USDA \\
\hline NRDum & $=1$ if $\mathrm{NR} \neq 0,=0$ if $\mathrm{NR}=0$ & EIA, USGS \\
\hline $\begin{array}{l}(\text { dOil } \\
\text { Price })^{*}(N R D u m)\end{array}$ & $\begin{array}{l}\text { Interaction variable between the percent change in real } \\
\text { oil price over the time period, and NRDum indicator } \\
\text { variable }\end{array}$ & EIA, USGS \\
\hline CoalO & $\begin{array}{l}=1 \text { if county has ever produced coal as of initial year of } \\
\text { period }\end{array}$ & EIA, USGS \\
\hline$N R$ & $\begin{array}{l}\text { Coal revenue (price* production) divided by total county } \\
\text { personal income, during initial year of period }\end{array}$ & EIA, USGS \\
\hline Year XXXX & Year fixed effect & - \\
\hline SlavePct 1860 & $\begin{array}{l}\text { Percentage of population that were slaves in } 1960 \\
\text { Share of population age } 25+\text { with no high school }\end{array}$ & Census \\
\hline Dropout & $\begin{array}{l}\text { diploma } \\
\text { Share of population age } 25+\text { with a college degree or }\end{array}$ & \\
\hline Bach+ & $\begin{array}{l}\text { higher } \\
\text { Share of the work force employed in educational }\end{array}$ & Census \\
\hline$E m p E d u$ & services & Census \\
\hline EduExpShare & $\begin{array}{l}\text { Share of educational expenditures in total county } \\
\text { expenditures }\end{array}$ & $\begin{array}{l}\text { Census of } \\
\text { Govt }\end{array}$ \\
\hline Enroll & $\begin{array}{l}\text { Share of school age children enrolled in elementary or } \\
\text { high school }\end{array}$ & Census \\
\hline Age65Up & Share of the population age 65 and over & $\begin{array}{l}\text { Census } \\
\text { Census of }\end{array}$ \\
\hline PropTaxPC & Property tax revenue per capita in county $\mathrm{i}$ & $\begin{array}{l}\text { Govt } \\
\text { Census of }\end{array}$ \\
\hline TotTaxPC & Total (County) tax revenue per capita in county $i$ & Govt \\
\hline
\end{tabular}


Appendix 2: Variable Descriptive Statistics

\begin{tabular}{lccccc} 
Variable & Obs & Mean & Std. Dev. & Min & Max \\
\hline \hline git & 1636 & 0.012 & 0.013 & -0.033 & 0.093 \\
LnY(it) & 1636 & 9.493 & 0.304 & 8.322 & 10.463 \\
Metro County & 1636 & 0.269 & 0.444 & 0 & 1 \\
Rural County & 1636 & 0.438 & 0.496 & 0 & 1 \\
NRDum & 1636 & 0.347 & 0.476 & 0 & 1 \\
(dOil Price)*(NRDum) & 1636 & 0.127 & 0.626 & -0.940 & 1.650 \\
CoalO & 1636 & 0.466 & 0.499 & 0 & 1 \\
NR & 1636 & 0.110 & 0.342 & 0 & 3.997 \\
SlavePct1860 & 1636 & 6.781 & 7.901 & 0 & 43.900 \\
Dropout & 1636 & 0.453 & 0.171 & 0.086 & 0.874 \\
Bach+ & 1636 & 0.097 & 0.055 & 0.013 & 0.475 \\
EmpEdu & 1636 & 0.084 & 0.038 & 0.021 & 0.380 \\
EduExpShare & 1635 & 0.198 & 0.290 & 0.000 & 0.881 \\
Enroll & 1636 & 0.183 & 0.050 & 0.072 & 0.302 \\
Age65Up & 1636 & 0.132 & 0.028 & 0.047 & 0.259 \\
PropTaxPC & 1635 & 0.078 & 0.095 & 0.001 & 1.724 \\
TotTaxPC & 1635 & 0.118 & 0.143 & 0.004 & 1.853 \\
\hline \hline
\end{tabular}

Appendix 3: USGS Topography Codes

\begin{tabular}{|c|c|}
\hline Plains & Open Hills and Mountains \\
\hline 1 = Flat plains & $13=$ Open low hills \\
\hline 2 = Smooth plains & $14=$ Open hills \\
\hline 3 = Irregular plains, slight relief & $15=$ Open high hills \\
\hline 4 = Irregular plains & $16=$ Open low mountains \\
\hline Tablelands & $17=$ Open high mountains \\
\hline 5 = Tablelands, moderate relief & Hills and Mountains \\
\hline $6=$ Tablelands, considerable relief & $18=$ Hills \\
\hline 7 = Tablelands, high relief & $20=$ Low mountains \\
\hline $8=$ Tablelands, very high relief & $21=$ High mountains \\
\hline & \\
\hline Plains with Hills or Mountains & \\
\hline 9 = Plains with hills & \\
\hline 10 = Plains with high hills & \\
\hline $11=$ Plains with low mountains & \\
\hline
\end{tabular}


Appendix 4: Growth Regression Results with State-Time Fixed Effect

Dependent Variable: Annualized Growth Rates of Per Capita Personal Income 1970-2008

Sample Size: $\mathrm{T}=4$ (1970-2008), N=409 Counties, total obs. $=1636$

\begin{tabular}{lcccc}
\hline \hline & ALL & \multicolumn{3}{c}{ APPALACHIAN } \\
\cline { 3 - 5 } & COUNTIES & BROAD & CORE & ARC \\
\hline Intercept & $0.1091^{* * *}$ & $0.1476^{* * *}$ & $0.1838^{* * *}$ & $0.1688^{* * *}$ \\
& $(0.0295)$ & $(0.0191)$ & $(0.0335)$ & $(0.0272)$ \\
Initial Income & $-0.0110^{* * *}$ & $-0.0156^{* * *}$ & $-0.0179^{* * *}$ & $-0.0169^{* * *}$ \\
Metro & $(0.0030)$ & $(0.0020)$ & $(0.0035)$ & $(0.0028)$ \\
& $0.0043^{* * *}$ & $0.0036^{* * *}$ & $0.0030^{* * *}$ & $0.0037^{* * *}$ \\
Rural & $(0.0007)$ & $(0.0008)$ & $(0.0009)$ & $(0.0009)$ \\
& -0.0010 & -0.0006 & -0.0011 & -0.0005 \\
dOilPrice*Coal0 & $(0.0007)$ & $(0.0008)$ & $(0.0007)$ & $(0.0009)$ \\
& $0.0054^{* * *}$ & $0.0056^{* * *}$ & $0.0045^{* * *}$ & $0.0055^{* * *}$ \\
Coal0 & $(0.0011)$ & $(0.0016)$ & $(0.0012)$ & $(0.0015)$ \\
& $-0.0038^{* * *}$ & $-0.0036^{* *}$ & -0.0022 & $-0.0027 * *$ \\
\#Counties & $(0.0009)$ & $(0.0013)$ & $(0.0014)$ & $(0.0011)$ \\
sigma_u & & & & \\
sigma_e & 1069 & 409 & 205 & 420 \\
rho & 0.0048 & 0.0074 & 0.0093 & 0.0065 \\
R-squared & 0.0101 & 0.0093 & 0.0096 & 0.0093 \\
Within & 0.1875 & 0.3828 & 0.4833 & 0.3257 \\
Between & & & & \\
Overall & 0.3983 & 0.4702 & 0.4353 & 0.4691 \\
\hline \hline Robust stang & 0.0321 & 0.0343 & 0.1786 & 0.0661 \\
& 0.3253 & 0.2503 & 0.2340 & 0.3283 \\
\hline
\end{tabular}

Robust standard errors in parenthesis.

* Significant at $10 \%$; * significant at 5\%; *** significant at $1 \%$ 
Appendix 5: ARC County Economic Status in Appalachia, FY 2008

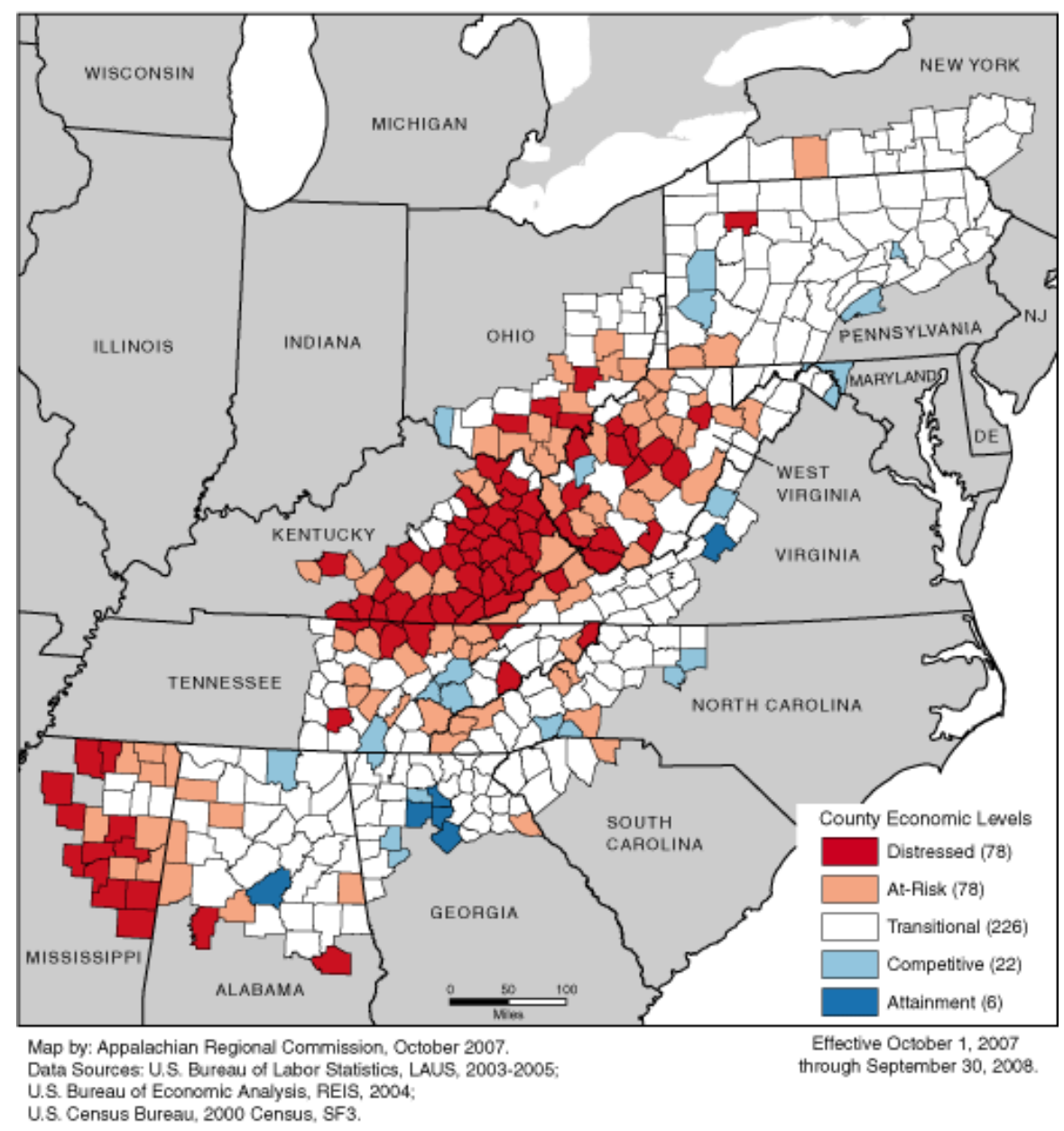

Appendix 6: Rural-Urban Continuum Codes (Beale Codes, USDA)

\begin{tabular}{|l|l|}
\hline Code & \multicolumn{1}{|c|}{ Description } \\
\hline & Metro counties: \\
\hline 1 & Counties in metro areas of 1 million population or more \\
\hline 2 & Counties in metro areas of 250,000 to 1 million population \\
\hline 3 & Counties in metro areas of fewer than 250,000 population \\
\hline & Nonmetro counties: \\
\hline 4 & Urban population of 20,000 or more, adjacent to a metro area \\
\hline 6 & Urban population of 20,000 or more, not adjacent to a metro area \\
\hline 7 & Urban population of 2,500 to 19,999, adjacent to a metro area \\
\hline 8 & Urban population of 2,500 to 19,999, not adjacent to a metro area \\
\hline 9 & Completely rural or less than 2,500 urban population, adjacent to a metro area \\
\hline & $\begin{array}{l}\text { Completely rural or less than 2,500 urban population, not adjacent to a metro } \\
\text { area }\end{array}$ \\
\hline
\end{tabular}




\section{REFERENCES}

Acemoglu, Daron, Simon Johnson, and James Robinson. (2001). "The Colonial Origins of Comparative Development: An Empirical Investigation,” American Economic Review. 91(5): 1369-1401.

Acemoglu, Daron, Simon Johnson, and James Robinson. (2002). "Reversal of Fortune: Geography and Institutions in the Making of the Modern World Income Distribution," Quarterly Journal of Economics. 117(4): 1231-1294.

Acemoglu, Daron, James A Robinson, and Thierry Verdier. (2003). "Kleptocracy and Divide-and-Rule: A Model of Personal Rule.” CEPR Discussion Paper.

ARC. (1964) “Appalachia: A Report by the President's Appalachian Regional Commission,” USGPO. Downloaded from http://www.arc.gov/.

Auty, Richard M. (2001) Resource Abundance and Economic Development. Oxford: Oxford University Press.

Auty, Richard M. (1997). "Natural Resource Endowment, the State and Development Strategy." Journal of International Development, 9(4): 651-63.

Barbier, Edward B. (2005) Natural Resources and Economic Development. Cambridge and New York: Cambridge University Press.

Barro, R. J. (1991). Economic growth in a cross section of countries. The Quarterly Journal of Economics, 106(2), 407-443. doi:10.2307/2937943

Barro, R. J., \& Lee, J. (2000). International data on educational attainment: Updates and implications. Unpublished manuscript.

Barro, Robert, and Xavier Sala-i-Martin. (1999). Economic Growth. Cambridge, Massachusetts: MIT Press.

Becker, Gary. (1964). Human Capital: A Theoretical and Empirical Analysis with Special Reference to Education.New York: Columbia University Press.

Berry, W. D., \& Fording, R. C. (1997). Measuring state tax capacity and effort. SOCIAL SCIENCE QUARTERLY-AUSTIN, 78, 158-166.

Bils, M., \& Klenow, P. J. (2000). Does schooling cause growth? American Economic Review, 90(5), 1160-1183.

Black, Dan A., Terra G. McKinnish, and Seth G. Sanders. (2005a). Tight labor markets and the demand for education: Evidence from the coal boom and bust. Industrial and Labor Relations Review 59 (1) (10): 3-16.

Black, Dan, Terra McKinnish, and Seth Sanders. (2005b) The Economic Impact of the Coal Boom and Bust, Economic Journal, 115, 449-476.

Blankenau, W. F., Simpson, N. B., \& Tomljanovich, M. (2007). Public education expenditures, taxation, and growth: Linking data to theory. The American Economic Review, 97(2), 393-397.

Boschini, Anne D., Jan Pettersson, and Jesper Roine. (2007). "Resource Curse or Not: A Question of Appropriability.” Scandinavian Journal of Economics, 109(3): 593-617.

Bradshaw, Michael. (1992) The Appalachian Regional Commission: Twenty-Five Years of Government Policy. University Press of Kentucky: Lexington, KY.

Brunnschweiler, C. N. and E. H. Bulte. (2008). "The Resource Curse Revisited and Revised: A Tale of Paradoxes and Red Herrings," Journal of Environmental Economics and Management, 55, 248-264.

Brunnschweiler, C. N. "Cursing the Blessings? (2008). Natural Resource Abundance, Institutions, and Economic Growth," World Development, 36, 399-419.

Bulte, Erwin H., Richard Damania, and Robert T. Deacon. (2005). "Resource Intensity, Institutions, and Development." World Development, 33(7): 1029-44. 
Cameron, S. V., \& Heckman, J. J. (1993). Trends in college entry among whites, blacks, and hispanics: Comment. In C. T. Clotfelter, \& M. Rothschild (Eds.), (pp. 105-119) A National Bureau of Economic Research Project Report; Chicago and London; University of Chicago Press.

Cameron, S. V., \& Heckman, J. J. (2001). The dynamics of educational attainment for black, hispanic, and white males. Journal of Political Economy, 109(3), 455-499.

Card, David. (2001) "Estimating the Return to Schooling: Progress on Some Persistent Econometric Problems," Econometrica, 69: 5

Card, David. (1993). "Using geographic variation in college proximity to estimate the return to schooling" (No. w4483). National Bureau of Economic Research.

Caselli, Francesco, Gerardo Esquivel and Fernando Lefort. (1996). Reopening the Convergence Debate: A New Look at Cross-Country Growth Empirics. Journal of Economic Growth Vol. 1, No. 3, pp. 363-389.

Caselli, Francesco, and Guy Michaels, G. (2013). Do Oil Windfalls Improve Living Standards? Evidence from Brazil. American Economic Journal: Applied Economics, 5(1), 208-238.

Caselli, Francesco, and Guy Michaels, G. (2009). Do Oil Windfalls Improve Living Standards? Evidence from Brazil. Working Paper.

Cohn, E., \& Hughes, W. W., Jr. (1994). A benefit-cost analysis of investment in college education in the United States: 1969-1985. Economics of Education Review, 13(2), 109-123.

Collier, Paul. (2010). The Plundered Planet. Oxford University Press.

Corey, Joab. (2008) "Three Essays on Resources, Institutions, and Development across U.S. States," unpublished dissertation, West Virginia University.

Cullison, W., (1993). Public investment and economic growth. Federal Reserve Bank of Richmond Economic Quarterly 79, 19- 33.

Currie, J., \& Moretti, E. (2003). Mother's education and the intergenerational transmission of human capital: Evidence from college openings. The Quarterly Journal of Economics, 118(4), 1495-1532.

Deaton, B. James and Ekaterina Niman. (2012) "An Empirical Examination of the Relationship Between Mining Employment and Poverty in the Appalachian Region," Applied Economics, 44, 303-312.

Devarajan, S., Swaroop, V., \& Zou, H. F. (1996). The composition of public expenditure and economic growth. Journal of monetary economics, 37(2), 313-344.

Douglas, Stratford, Anne Walker. (2012) Sample Selection in Appalachian Research. Review of Regional Studies, 42(2): 143-159.

Dunn, Leslie. (2008) "Three Essays on Development in Specialized Economies: The Resource Curse in U.S. States and Small Island Economies," unpublished Dissertation, West Virginia University.

Easterly, W., \& Rebelo, S. (1993). Fiscal policy and economic growth. Journal of monetary economics, 32(3), 417-458.

Engemann, Kristie M., Michael T. Owyang, and Howard J. Wall. (2011). Where is an Oil Shock? St. Louis Federal Reserve Working Paper 2011-016A.

Feranadez, Raquel and Richard Rogerson. (2001). The Determinants of Public Education Expenditures: Longer-Run Evidence from the States. Journal of Education Finance, 27: 567-584.

Fishcer, David Hackett. (1989) Albion's Seed: Four British Folkways in America. Oxford University Press: New York.

Glaeser, Edward and Joshua Gottlieb. (2008) "The Economics of Place Making Policies," Brookings Papers on Economic Activity, 1(Spring), 155-253.

Goetz, S. J., \& Hu, D. (1996). Economic growth and human capital accumulation: Simultaneity and expanded convergence tests. Economics Letters, 51(3), 355-362. 
Goldberg, E., Wibbels, E., \& Mvukiyehe, E. (2008). Lessons from Strange Cases Democracy, Development, and the Resource Curse in the US States.Comparative Political Studies, 41(4-5), 477514.

Gylfason, Thorvaldur. (2001). Natural resources, education, and economic development. European Economic Review 45 (4-6) (5): 847-59.

Gylfason, Thorvaldur, Tryggvi Thor Herbertsson, and Gylfi Zoega. (1999). A mixed blessing: Natural resources and economic growth. Macroeconomic Dynamics 3 (2) (06): 204-25.

Harkness, Kristen A. (2010) "Escaping the Resource Curse: Lessons from Kentucky Coal Counties," unpublished paper presented at APSA 2009 Toronto Meeting. Available at SSRN: http://ssrn.com/abstract=1450181.

Heckman, James J. (1979) "Sample Selection Bias as a Specification Error," Econometrica, 47, 157-161.

Higgins, Matthew J., Daniel Levy, and Andrew T. Young. (2006) "Growth and Convergence across the U.S: Evidence from County Level Data," Review of Economics and Statistics, 88, 671-681.

Hoyt, W. H. (2003). Differences in tax bases and tax effort across Kentucky counties. Working Paper, Lexington, KY: Center for Business and Economic Research (CBER), University of Kentucky.

Hy, R. J., Boland, C., Hopper, R., \& Sims, R. (1993). Measuring revenue capacity and effort of county governments: A case study of Arkansas. Public Administration Review, 220-227.

Isham, Jonathan, Michael Woolcock, Lant Pritchett, and Gwen Busby. (2005). The varieties of resource experience: Natural resource export structures and the political economy of economic growth. The World Bank Economic Review 19 (2) (January 01): 141-74.

Isserman, Andrew and Terrance Rephann. (1995) "The Economic Effects of the Appalachian Regional Commission," Journal of the American Planning Association, 61, 345-365.

James, Alex and David Aadland. (2011) "The Curse of Natural Resources: An Empirical Investigation of U.S. Counties," Resource and Energy Economics, 53, 440-453.

Kane, T. J., \& Rouse, C. E. (1995). Labor-market returns to two-and four-year college. The American Economic Review, 600-614.

Krueger, A. B., \& Lindahl, M. (2001). Education for growth: Why and for whom? Journal of Economic Literature, 39(4), 1101-1136.

Levine, R., \& Renelt, D. (1992). A sensitivity analysis of cross-country growth regressions. The American Economic Review, 942-963.

Maluccio, J. (1998). Endogeneity of schooling in the wage function: Evidence from the rural Philippines. Food Consumption and Nutrition Division Discussion Paper, 54.

Mankiw, Gregory, David Romer and David N. Weil. (1992). A Contribution to the Empirics of Economic Growth. The Quarterly Journal of Economics 107 (2): 407-437.

Marchand, J. (2012). Local labor market impacts of energy boom-bust-boom in western Canada. Journal of Urban Economics, 71(1), 165-174.

Mehlum, Halvor, Karl Moene, and Ragnar Torvik. (2006). Institutions and the resource curse. The Economic Journal 116 (508): 1-20.

Michaels, Guy. (2011) “The Long Term Consequences of Resource-based Specialisation,” Economic Journal, 121, 31-57.

Milici, Robert C. and Kristin O. Dennen. (2009). "Production and Depletion of Appalachian and Illinois Basin Coal Resources." Chapter H in The National Coal Resource Assessment Overview: U.S. Geological Survey Professional Paper 1625-F, 402, edsl, Pierce, B.S., and Dennen, K.O.

Mincer, Jacob. (1958). "Investment in Human Capital and Personal Income Distribution.” Journal of Political Economy, Vol. 66, No. 4 (August), pp.281-302.

Papyrakis, Elissaios and Reyer Gerlagh. (2007) "Resource abundance and economic growth in the United States," European Economic Review, 51, 1011-1139. 
Papyrakis, Elissaios, and Reyer Gerlagh. (2004). The resource curse hypothesis and its transmission channels. Journal of Comparative Economics 32 (1) (3): 181-93.

Partridge, Mark, Mike Betz, and Linda Lobao. (2012) Natural Resource Curse and Poverty in Appalachia, Forthcoming in the American Jounal of Agricultural Economics.

Poterba, J. M. (1998). Demographic change, intergenerational linkages, and public education. The American Economic Review, 88(2), 315-320.

Rappaport, J. (1999). Local growth empirics. Unpublished manuscript from http://www2.cid.harvard.edu/cidwp/023.pdf

Robinson, James A., Ragnar Torvik, and Thierry Verdier. (2006). Political foundations of the resource curse. Journal of Development Economics 79 (2) (4): 447-68.

Ross, Michael L. (1999) The Political Economy of the Resource Curse, World Politics, 51, 297-322.

Ross, Michael L. (2004). How do natural resources influence civil war? Evidence from thirteen cases. International Organization 58 (1) (Winter): 35-67,

Ross, Michael L. (2001). Does oil hinder democracy? World Politics, 53(03), 325.

Sachs, Jeffrey D. and Andrew M. Warner. (2001) The Curse of Natural Resources, European Economic Review, 45, 827-838.

Sachs, Jeffrey D. and Andrew M. Warner. (1997) Sources of Slow Growth in African Economies, Journal of African Economies, 6, 335-376.

Sachs, Jeffrey D. and Andrew M. Warner. (1995) Natural Resource Abundance and Economic Growth, NBER Working Paper 5398. National Bureau of Economic Research, Inc.: Boston, MA.

Santopietro, George D. (2002). Analyzing Income Convergence at the County Level: The Case of Development in Central Appalachia. Journal of Economic Issues, Vol. 36, No. 4, pp. 893-906.

Sen, Arzu. (2010) Essays on Housing Markets and Economic Growth, Unpublished Ph.D. Dissertation, West Virginia University.

Stijns, J-P. C. (2005). Natural Resource Abundance and Economic Growth Revisited, Resources Policy, 30, 107-130.

Temple, J. (1999). The new growth evidence. Journal of economic Literature,37(1), 112-156.

Topel, R. (1999). Labor markets and economic growth. In O. Ashenfelter, \& D. Card (Eds.), (pp. 29432984) Handbooks in Economics, vol. 5; Amsterdam; New York and Oxford; Elsevier Science, NorthHolland.

USGS. (1970) National Atlas of the United States of America, U.S. Geological Survey, US Dept of Interior: Washington, DC.

Uusitalo, R. \& Conneely, K., (1998). "Estimating Heterogeneous Treatment Effects in the Becker Schooling Model," University of Helsinki, Department of Economics.

van der Ploeg, Frederick. (2011) "Natural Resources: Curse or Blessing?," Journal of Economic Literature, 49, 366-420.

Woolcock, Michael, Lant Pritchett, and Jonathan Isham. (2001). "The Social Foundations of Poor Economic Growth in Resource-Rich Countries." In Resource Abundance and Economic Development, ed. R. M. Auty, 76-92. Oxford and New York: Oxford University Press.

Young, A.T., Higgins, M.J. \& Levy, D. (2008). Sigma convergence versus beta convergence: Evidence from U.S. county-level data. Journal of Money, Credit and Banking, 40(5), 1083-1093.

Zhang, Jie, and Richard Casagrande. (1998). "Fertility, Growth, and Flat-Rate Taxation for Education Subsidies." Economics Letters, 60(2): 209-16.

Ziliak, James P. (2011) “The Appalachian Regional Development Act and Economic Change," in James P. Ziliak (ed.), Appalachian Legacy: Economic Opportunity after the War on Poverty. Brookings Institution Press: Washington, DC, pp. 19-44. 